\title{
Preferred Conformations in the Intrinsically Disordered Region of Human CPEB3 Explain its Role in Memory Consolidation
}

\author{
Daniel Ramírez de Mingo ${ }^{1}$ David Pantoja-Uceda², Rubén Hervás ${ }^{3}$, \\ Mariano Carrión Vázquez ${ }^{1 *}$ and Douglas V. Laurents, ${ }^{2, *}$
}

Running Title: NMR Reveals Nascent hCPEB3 Structures

\author{
${ }^{1}$ Instituto Cajal, IC-CSIC, Avda. Doctor Arce 37, E-28002 Madrid, Spain. \\ ${ }^{2}$ Instituto de Química-Física Rocasolano, IQFR-CSIC, Serrano 119, E-28006 Madrid, \\ Spain. \\ ${ }^{3}$ Stowers Institute for Medical Research, Kansas City, MO, 64110, USA.
}

†To whom correspondence should be addressed:

MCV (mcarrion@cajal.csic.es), DVL (dlaurents@iqfr.csic.es)

\section{Highlights:}

- Human CPEB3's aggregation-prone disordered region is studied by NMR.

- In the monomeric state, the polyQ stretch is disordered and flexible.

- $5 \alpha$-helices, 2 PPII helices and a rigid nonpolar stretch are identified.

- Association of the first $4 \alpha$-helices could promote functional amyloid formation.

- The PPII helices could negatively regulate this process.

- The last $\alpha$-helix forms the NES and putatively regulates nucleocytoplasmic transport via STAT5B.

Key Words: nuclear magnetic resonance, memory consolidation, functional amyloids, intrinsically disordered proteins, amyloidogenic proteins 


\section{Short Summary}

Amyloids are implicated in neurodegenerative diseases, but they are also essential to several physiological processes, including memory consolidation, neuronal-specific isoforms of the Cytoplasmic Polyadenylation Element Binding (CPEB) protein family. Here, we characterize the atomic level conformation and ps-ns dynamics of the 426residue intrinsically disordered region (IDR) of human CPEB3 (hCPEB3), which has been associated with episodic memory in humans, by NMR spectroscopy. The first 29 residues: $\quad M_{1}{ }_{1}$ DDLLMDKSKTQPQPQQQQRQQQQQPQP 29 , adopt a helical+disordered motif, which is key for in vitro amyloid formation. Residues 86-93: $\mathrm{P}_{83} \mathrm{QQPPPP}_{93}$, and 166-175: $\mathrm{P}_{166} \mathrm{PPPAPAPQP}_{175}$ form polyproline II (PPII) helices. We advance that the presence of amyloid breaker residues, such as proline, is a key difference between functional versus pathological amyloids. While the $(\mathrm{VG})_{5}$ repeat motif is completely disordered, residues 200-250 adopt three partially populated $\alpha$-helices. Residues 345 - 355, which comprise the nuclear localization signal, form a modestly populated $\alpha$-helix and border a phosphoTyr which may mediate STAT5B binding. These findings allow us to advance a model for hCPEB3 structural transitions in memory consolidation in humans.

Table of Contents Graphic:

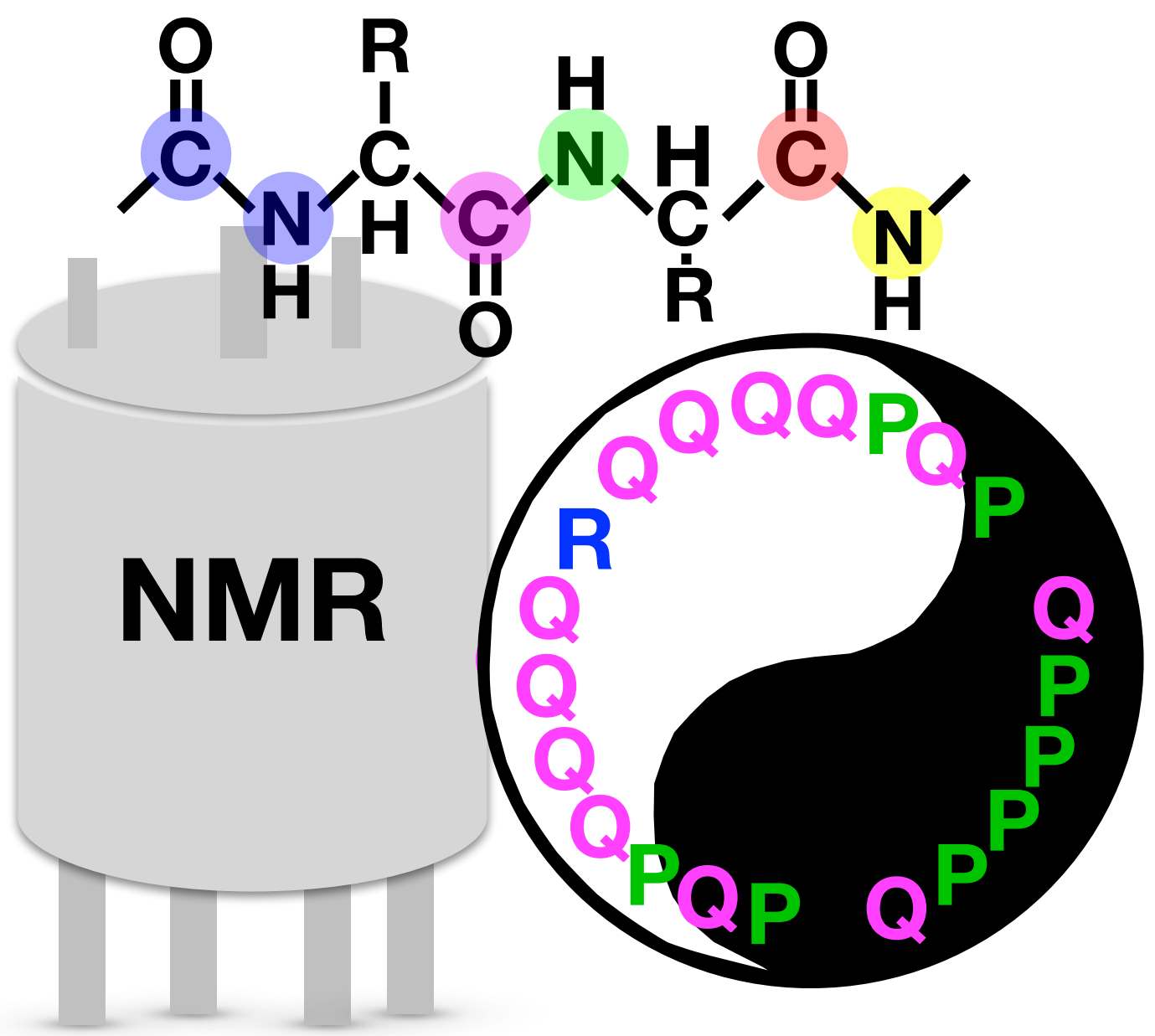




\begin{abstract}
Amyloids play key pathological roles in a score of neurodegenerative diseases, but they are also essential to several physiological processes. Perhaps the most fascinating functional amyloid is formed by the Cytoplasmic Polyadenylation Element Binding protein $(\mathrm{CPEB})$ protein family as its structural conversion is essential for memory consolidation in different animals. In vitro, CPEB amyloid formation is driven by the intrinsically disordered region (IDR) present in neuronal-specific isoforms. However, the underlying conformational transitions from the monomeric state to the amyloid state remain poorly understood. Here, we characterize the residue level conformational preferences and ps-ns dynamics for human CPEB3 (hCPEB3) by high field, heteronuclear NMR spectroscopy. At 426 residues, this is the second longest IDR characterized to date in such detail. We find that the residues 1-29: $\mathrm{M}_{1}$ QDDLLMDKSKTQPQPQQQQRQQQQQPQP ${ }_{29}$, adopt an $\alpha$-helical+disordered Qrich motif. Similar helix $+\mathrm{Q} / \mathrm{N}$-rich motifs are observed in CPEB homologs as well as other RNA-binding proteins like TDP-43 that form pathological amyloids. Residues 8693: $\mathrm{P}_{83} \mathrm{QQPPPP}_{93}$, and residues 166-175: $\mathrm{P}_{166} \mathrm{PPPAPAPQP}_{175}$ form polyproline-II (PPII) helices, and we propose NMR chemical shift-based criteria for identifying this conformation. We advance that the presence of helix and amyloid breaker residues, such as proline, in hCPEB3 and its absence in TDP-43 may be a key difference between the functional and pathological amyloids in higher eukaryotes. While the (VG) $)_{5}$ repeat motif (residues 272-282) appears to be completely disordered, residues S221-A235 form a highly populated, rather rigid $\alpha$-helix and two nearby segments adopt partially populated $\alpha$-helices. Residues 345-355 also form a partially populated $\alpha$-helix. These residues comprise the nuclear export signal and border a putative phosphoTyr site which may mediate STAT5B binding. Thus, nascent hCPEB3 protein is not fully disordered like a blank sheet of paper; instead, it contains creases which guide the engraving of our memories. Based on these findings and previous results, a working model for hCPEB3 structural transitions in human memory consolidation is advanced.
\end{abstract}




\section{Introduction}

The molecular basis of long-term memory, which endures decades despite being built by ephemeral biomolecules, has long fascinated biochemists (Crick, 1984). Seminal findings by Si, Lindquist and Kandel showed that long-term changes in synaptic efficacy require a self-perpetuating aggregative, and possibly amyloid, state in the Aplysia Cytoplasmic Polyadenylation Element Binding protein (CPEB) (Si et al., 2003). This change in CPEB's conformation leads to permanent alterations at the synapse constituting a physical basis of memory storage. Aplysia CPEB contains an IDR that is very rich in glutamine residues. This Q-rich region, essential for acquiring the self-perpetuating state necessary to stabilize memory, losses $\alpha$-helix and gains $\beta$-sheet structure during amyloid formation in vitro (Raveendrea et al., 2013). However, polyQ expansions in Huntingtin protein (Jayaraman et al., 2012) and the Androgen Receptor (Escobedo et al., 2019) are known for their ability to form toxic aggregates in Huntington's disease and in spinobulbar muscular atrophy, respectively. Interestingly enough, Huntingtin protein has been proposed to play a role in memory consolidation (Choi et al., 2014).

More recently, the Drosophila homolog of CPEB, called Orb2A, has been shown to behave in a similar fashion despite its lower glutamine residue content and more highly regulated amyloid formation (Majumdar et al., 2012; Khan et al., 2015). Indeed, inhibition of Orb2 amyloid formation specifically impairs memory consolidation, but not short-term memory in Drosophila (Majumdar et al., 2012; Hervás et al., 2016). Due to numerous His residues in the Orb2 amyloid core, $\mathrm{pH}$ regulates this structure's stability as shown in its recently elucidated structure (Hervás et al., 2020). In mammals, the Nterminal region of neuronal-specific isoform of CPEB3 is considered to be crucial for amyloid formation and memory consolidation (Fioriti et al., 2015; Stephan et al., 2015). The regulation of functional amyloid formation in mammalian CPEB3 appears to be even more sophisticated due to multiple variants, post-translational modifications (Drisaldi et al., 2015), and feedback loops to maintain hCPEB3 expression levels (Fiumara et al., 2015). Compared to the Aplysia and Drosophila homologs, hCPEB3's overall content of glutamine residues is lower. Its IDR is very long (426 residues) and contains diverse segments which are enriched for certain residues such as Gln, Ser, Ala, Pro, Gly+Val and hydrophobic residues (Table 1).

Beyond the fundamental biological interest in comprehending the molecular basis of long-term human memory, this understanding could also guide the development of treatments for Post-Traumatic Stress Disorder and other diseases associated with the storage of "pathological memories" (Hyman, 2005). Furthermore, like its homologs in Aplysia and Drosophila, hCPEB3 resembles the abundant and diverse superfamily of RNA-binding proteins that contain RNA-Recognition Motifs (RRM) and/or Zinc Fingers $(\mathrm{ZnF})$ domains as well as intrinsically disordered prion-like regions, such as Fused in Sarcoma (FUS) or Transactive Response DNA Binding Protein of $43 \mathrm{kDa}$ (TDP-43). FUS and TDP-43 are essential proteins, but their anomalous aggregation has been implicated in amyotrophic lateral sclerosis (ALS) and frontotemporal dementia (FTD) 
(Mackenzie et al., 2010). In addition, TDP-43 has been linked to the recently described Limbic-Predominant Age-Related TDP-43 Encephalopathy (LATE) (Nelson et al., 2019). Thus, the comparison of the physiologically relevant amyloid formation by hCPEB3 versus the aberrant amyloid formation by TDP-43 may reveal why the latter can become pathological.

Mammalian CPEB3 travels to several distinct neuronal regions to carry out multiple functions (Figure 1A). Following its synthesis, CPEB3 is SUMOlyated; which has been reported to block CPEB3 aggregation (Drisaldi et al., 2015). Upon neuronal stimulation, CPEB3, which is mostly cytoplasmic, travels to the nucleus. This process is mediated by the karyopherin IPO5 through interactions the nuclear localization signal (NLS) in the first RRM of hCPEB3 (Chao et al., 2012). Inside the nucleus, CPEB3 interacts with STAT5B, which normally activates the transcription of genes such as EGFR (Terlau \& Seifert 1989), that trigger signaling cascades thought to promote memory consolidation (Peng et al., 2010). CPEB3-STAT5B binding downregulates STAT5B-dependent transcription. This union is driven by interactions between the IDR of hCPEB3 and residues 639-700 of STAT5B, but the details of this interaction have not yet been addressed. By contrast, the 3D solution structure of the first CPEB3 RRM domain has been elucidated and revealed an additional $\beta$-hairpin (W471-G485) proposed to play a key role in RNA recognition (Tsuda et al., 2014). This domain, as well as the second RRM domain and ZnF motif, were reported to bind specifically to the 3'UTR of the GluR2 mRNA (Huang et al., 2006). Together, CPEB3 and its target mRNA eventually exit the nucleus. CPEB3 and its associated mRNA can join distinct biomolecular condensates, such as the stress granule during cellular stress, neuronal granules, which provide physiological transport to dendritic spines or to dendritic P-bodylike granules (Ford et al., 2019) where hCPEB3 stores and downregulates GluR2 mRNA translation (Huang et al., 2006). Upon neuronal stimulation, CPEB3 converts into an active state, through the IDR, that promotes target mRNA translation. This process is associated with a decreased SUMOylation of CPEB3 and an increased CPEB3 aggregation in hippocampal neurons (Drisaldi et al., 2015). This leads to structural modifications, including a more robust actin network, which fortify the spine and permanently enhance neurotransmission at this particular synapse (Stephan et al., 2015). The hypothesis that CPEB functional amyloid formation is key for memory persistence (Si et al., 2003) is supported by numerous in vitro experiments as well as studies in Aplysia, Drosophila and mammalian cells which have been reviewed (Si \& Kandel, 2016). The causal role of CPEB3 in memory is corroborated by observations that persons carrying a rare $C P E B 3$ allele, which leads to a decreased production of hCPEB3 protein, have episodic memory impairments (Vogler et al., 2009).

The 426 residue long IDR of hCPEB3 contains an amyloid-forming prion like domain (PLD) spanning residues 1-253, while the remaining residues, 254-426, promote liquid-liquid phase separation (Ramírez de Mingo et al., 2020). The complete IDR (residues 1-426) is followed by two folded RRM which bind RNA and finally a ZZ-type $\mathrm{ZnF}$ domain. The complete domain structure as well as segments which are found here to be structurally and functionally important are shown in Figure 1B. Recent sequence and deletion mutational analyses of the IDR have begun to identify subregions key for 
aggregation, such as the first 30 residues (Stephan et al., 2015). Programs to predict secondary structure tendencies give different outputs and to date, no high-resolution experimental data on the partial structures or motions of the hCPEB3 IDR have been reported. Here, motivated by the key roles of the IDR in CPEB3 functions in transcription via association with STAT5B, as well as CPEB aggregation-dependent synaptic protein synthesis, we characterize the atomic level conformation and dynamics of the complete IDR of hCPEB3 by NMR spectroscopy and propose a mechanism for CPEB3 aggregation.

\section{Materials \& Methods}

1. Materials: ${ }^{15} \mathrm{NH}_{4} \mathrm{Cl}$ and ${ }^{13} \mathrm{C}$-glucose were purchased Tracertec (Madrid, Spain), $\mathrm{D}_{2} \mathrm{O}$, was a product of Euroisotop, deuterated acetic acid was from Sigma/Aldrich and 4,4dimethyl-4-silapentane-1-sulfonic acid (DSS) as the internal chemical shift reference, was from Stolher Isotopes Chemical Company.

A twelve residue peptide, called hCPEBpep1, whose sequence corresponds to the protein's first 12 residues $\left(\mathrm{M}_{1} \mathrm{QDDLLMDKSKT} \mathrm{T}_{12}\right)$ and a twenty residue peptide, called hCPEBpep2 whose sequence corresponds to residues P91 PPQEPAAPGASLSPSFGST 110 in hCPEB3 were purchased from Genscript. hCPEBpep2's sequence overlaps with the C-terminal of Segment 1 and the N-terminus of Segment 3. The peptides were over 95\% pure, as assessed by HPLC, and their identities were confirmed by mass spectrometry and NMR spectroscopy.

2. Sample Production: Coding mRNAs of hCPEB3 vary in length due to an embedded human delta virus-like ribozyme which slowly splices out introns, leading to the generation of multiple isoforms (Salehi-Ashtiani et al., 2006). It is also noteworthy that Orb2A's pre-mRNA contains an intron with multiple stop codons which is only spliced out when certain "memorable" stimuli are experienced (Gill et al., 2017). Here, the hCPEB3 isoform 2, Uniprot Q8NE35-2 / Genebank CAI14105.1, is studied.

Plasmid construction, protein expression and purification. The hCPEB3 IDR, which corresponds to the first 426 residues of the protein whose sequence is shown in Table 1, was expressed at eight highly overlapping one-hundred residue segments. To control for end effects as well as to check the reproducibility of the results, each segment overlapped by 50 residues with the preceding and successive segment.

Each segment was cloned into the pET-28a(+) by PCR using the full length human CPEB3-2 in pLL3.7 plasmid as the template kindly provided by Dr. Yi-Shuian Huang (Huang et al., 2014). The DNA amplified fragments were digested with XhoI and NheI. Expression of the resulting clones led to fusion proteins containing a $\mathrm{His}_{6}$ tag and a TEV NI $\alpha$ protease cleavage site. Thus, each segment studied had the sequence: MGSSHHHHHHSSGLVPRGSHMASENLYFQ, at its N-terminus.

All overlapping segments were expressed in the E. coli BL21 Star (DE3) strain using the $\mathrm{T} 7$ expression system (Novagene). ${ }^{13} \mathrm{C} /{ }^{15} \mathrm{~N}$ isotopic labelling of each segment 
was done by using a previously published protocol (Marley et al., 2001). Briefly, cells were grown in $1 \mathrm{~L}$ of $\mathrm{LB}$ at $37^{\circ} \mathrm{C}$ by shaking at $280 \mathrm{rpm}$ upon reaching optical cell densities at $595 \mathrm{~nm}\left(\mathrm{OD}_{595}\right) \sim 0.6-0.7$. Cells were pelleted by a 30 min centrifugation at $5000 \times \mathrm{g}$ and washed using a $\mathrm{M} 9$ salt solution $\left(15.0 \mathrm{~g} / \mathrm{L} \mathrm{KH}_{2} \mathrm{PO}_{4}, 34.0 \mathrm{~g} / \mathrm{L} \mathrm{Na}_{2} \mathrm{HPO}_{4}\right.$ and $2.5 \mathrm{~g} / \mathrm{L} \mathrm{NaCl}$ for $1 \mathrm{~L}$ of $5 \times \mathrm{M} 9$ salts) excluding nitrogen and carbon sources. Cell pellets were resuspended in $250 \mathrm{~mL}$ of isotopically labelled minimal media M9 salt solution supplemented with ${ }^{13} \mathrm{C}$ D-glucose $4.0 \mathrm{~g} / \mathrm{L}$ and ${ }^{15} \mathrm{NH}_{4} \mathrm{Cl} 1.0 \mathrm{~g} / \mathrm{L}$ (Cambridge Isotope Laboratories, Inc.), then incubated to allow the recovery of growth and clearance of unlabeled metabolites. Protein expression was induced after $1 \mathrm{~h}$ by addition of IPTG to a concentration of $1 \mathrm{mM}$. After a $4.5 \mathrm{~h}$ incubation period, the cells were harvested.

Cell pellets were lysed with buffer with the following composition: $50 \mathrm{mM}$ $\mathrm{NaH}_{2} \mathrm{PO}_{4} / \mathrm{Na}_{2} \mathrm{HPO}_{4}, 500 \mathrm{mM} \mathrm{NaCl}, 50 \mathrm{mM}$ imidazole, $6 \mathrm{M}$ guanindium chloride $(\mathrm{GdmCl}), \mathrm{pH} 7.4$ and then sonicated. Each recombinant segment was purified by $\mathrm{Ni}^{2+}$ affinity chromatography using HisTrap HP purification columns with a FPLC system (ÄKTA Purifier, GE Healthcare) with elution buffer consisting in $50 \mathrm{mM}$ $\mathrm{NaH}_{2} \mathrm{PO}_{4} / \mathrm{Na}_{2} \mathrm{HPO}_{4}, 500 \mathrm{mM} \mathrm{NaCl}, 500 \mathrm{mM}$ imidazole, $6 \mathrm{M} \mathrm{GdmCl}$, pH 7.4.

If necessary, the pure segments were then incubated with TEV NI $\alpha$ protease $\mathrm{O} / \mathrm{N}$ at $4^{\circ} \mathrm{C}$ (Nallamsetty et al., 2004). The cleaved protein was then subjected to dialysis and recovered. Protein samples were stored at $-80^{\circ} \mathrm{C}$ until use. Eventually, they were desalted to $1 \mathrm{mM}$ DAc, $\mathrm{pH} 4.0$ by gel filtration chromatography using a PD-10 column (GE Healthcare), and concentrated to a final protein concentration of $1.0-1.5 \mathrm{mM}$ in $250 \mu \mathrm{L}$ using a Vivaspin microfiltration device and placed in a $5 \mathrm{~mm}$ Shigemi reduced volume NMR tube for measurements.

Non-labeled full length hCPEB3-IDR expression and purification was carried out essentially as described in the companion paper (Ramírez de Mingo et al. 2020). Briefly, cells were grown in $1 \mathrm{~L}$ of $\mathrm{LB}$ medium at $37^{\circ} \mathrm{C}$ until reaching an $\mathrm{OD}_{600}=0.6-0.7$ and protein expression was induced for 4 hours by adding IPTG at $1 \mathrm{mM}$ final concentration. Cells were harvested and following sonication, then lysed with buffer $50 \mathrm{mM} \mathrm{Na}_{2} \mathrm{HPO}_{4}$, $500 \mathrm{mM} \mathrm{NaCl}, 50 \mathrm{mM}$ imidazole, $6 \mathrm{M} \mathrm{GdmCl} \mathrm{pH} \mathrm{7.4.} \mathrm{After} \mathrm{centrifugation} \mathrm{at} 18000 \mathrm{rpm}$ for $45 \mathrm{~min}$, supernatants were purified with $\mathrm{Ni}^{++}$affinity chromatography and elution was performed in buffer $50 \mathrm{mM} \mathrm{NaPO}_{4}, 500 \mathrm{mM} \mathrm{NaCl}, 500 \mathrm{mM}$ imidazole, $3 \mathrm{M} \mathrm{GdmCl}$, pH 7.4. Purified CPEB3-IDD was diluted to PBS, $1 \mathrm{M} \mathrm{GdmCl} \mathrm{pH} \mathrm{7.4,} \mathrm{dialysed} \mathrm{against} \mathrm{PBS}$ $\mathrm{pH} 7.4$ at $4^{\circ} \mathrm{C}$ and finally concentrated by using Amicon Ultra- 15 centrifugal filters 10 kDa cut-off.

3. Sequence alignment: The conservation of vertebrate CPEB3 protein sequences was assessed using the programs T-coffee (Di Tiomasso et al., 2011) and Clustal Omega (Sievers et al., 2011) using the default settings. The sequences chosen as representative are human isoform 1 NP_001171608.1, human isoform 2 CAI14105.1, mouse NP_001277755.1, chicken XP_105144323.1, turtle (Chrysemys picta belli) XP_005301348.1, frog NP.001015925.1 (Xenopus tropicalis) and fish (Danio rerio) XP_009305819.1. 
4. NMR Spectroscopy: Instrumentation: All spectra for the hCPEB3 segments were recorded on a Bruker $800 \mathrm{MHz}\left({ }^{1} \mathrm{H}\right)$ Avance spectrometer fitted with a triple resonance TCI cryoprobe and Z-gradients. The ${ }^{1} \mathrm{H}$ chemical shift was referenced to $50 \mu \mathrm{M}$ DSS measured in the same buffer and at the same temperatures as those used for the CPEB3 segments. Since DSS can sometimes bind to instinsically disordered proteins (DiezGarcía et al., 2012) the DSS signal was recorded in an independent reference tube containing the same buffer at the same temperature. The ${ }^{13} \mathrm{C}$ and ${ }^{15} \mathrm{~N}$ chemical shift references values were calculated by multiplying by their respective gyromagnetic ratios with ${ }^{1} \mathrm{H}$; that is $\Xi{ }^{13} \mathrm{C} /{ }^{1} \mathrm{H}=0.251449530$ and $\Xi{ }^{15} \mathrm{~N} /{ }^{1} \mathrm{H}=0.101329118$ (Markley et al., 1998). NMR spectra were recorded and transformed using TOPSPIN (versions 2.1) (Bruker Biospin).

Nonconventional Assignment Strategy: To speed and improve the assignment of the backbone, we used a "proton-less" NMR approach for segments 1, 4, 5, 6 and 8 based on 2D CON spectra in which successive ${ }^{15} \mathrm{~N}-{ }^{13} \mathrm{CO}$ nuclei correlations are obtained in two 3D spectra called hacacoNcaNCO and hacaCOncaNCO (Pantoja-Uceda \& Santoro, 2014). For segments 7 and 8, which tend to form condensates (Ramírez de Mingo et al., 2020) and seem to be more rigid, this strategy afforded less intense spectra and in particular about $35 \mathrm{CON}$ crosspeaks were missing. Therefore, an additional strategy based on ${ }^{13} \mathrm{CO}$ connectivities from $3 \mathrm{D} \mathrm{HNCO}$ and $\mathrm{HNcaCO}$ spectra, as well as ${ }^{1} \mathrm{HN}$ and ${ }^{15} \mathrm{~N}$ connectivities of consecutive residues from 3D HncocaHN and hNcocaNH spectra (Sun et al., 2005; Pantoja-Uceda \& Santoro, 2009) was utilized to check and complete the backbone assignments. The latter strategy was also employed for segment 3 , which was less soluble. For all segments, further corroboration was obtained by conventional 2D ${ }^{1} \mathrm{H}-{ }^{15} \mathrm{~N}$ HSQC and 3D HNCO spectra as well as 3D CCCON to confirm the residue identity and obtain the chemical shift values of ${ }^{13} \mathrm{C}$ nuclei of the side chain.

Of the eight segments, only segment 2 failed to yield a soluble sample. Whereas the sequence assignments are complete thanks to the analysis of segments 1 and 3 , to test for possible end effects, a 20 residue peptide, hCPEBpep2, corresponding to residues 91110 of the hCPEB3 sequence was assigned and characterized structurally by $2 \mathrm{D}{ }^{1} \mathrm{H}-{ }^{1} \mathrm{H}$ COSY, ${ }^{1} \mathrm{H}-{ }^{1} \mathrm{H}$ TOSCY, ${ }^{1} \mathrm{H}-{ }^{1} \mathrm{H}$ NOESY and $2 \mathrm{D}{ }^{1} \mathrm{H}-{ }^{13} \mathrm{C}$ HSQC NMR spectra at $5.0{ }^{\circ} \mathrm{C}$ on a Bruker $600 \mathrm{MHz}$ spectrometer fitted with a cryoprobe and Z-gradients. A $2 \mathrm{D}{ }^{1} \mathrm{H}-{ }^{15} \mathrm{~N}$ HSQC was also recorded on the $800 \mathrm{MHz}$ Bruker spectrometer. Both the ${ }^{1} \mathrm{H}^{-15} \mathrm{~N}$ HSQC and the ${ }^{1} \mathrm{H}-{ }^{13} \mathrm{C}$ HSQC spectra were recorded at the natural abundance of ${ }^{15} \mathrm{~N}$ and ${ }^{13} \mathrm{C}$. The program NMRFAM-Sparky (Lee et al., 2015) was used to facilitate manual spectral assignment. The NMR spectral parameters are summarized in Sup. Table 1.

Theoretical chemical shift values for statistical coil ensembles were calculated using the parameters tabulated by Kjaergaard and Poulsen (2011) and Kjaergaard et al., (2011), as implemented on the https://spin.niddk.nih.gov/bax/nmrserver/Poulsen_rc_CS/ server at the Bax laboratory. These values were used to calculate conformational chemical shifts. When appropriate, representative preferred conformers were calculated using the program CYANA 3.98 (Günter \& Buchner, 2015). 
Coupling Constants: For segment 5, as an additional, independent test, a 3D HNHA spectrum were recorded and the ratio of the ${ }^{1} \mathrm{H} \alpha-{ }^{1} \mathrm{HN}$ crosspeak to the ${ }^{1} \mathrm{HN}-{ }^{1} \mathrm{HN}$ diagonal peak intensities in the 3D HNHA spectrum was utilized to calculate the ${ }^{3} \mathrm{~J}_{\mathrm{HNCH} \alpha}$ coupling constants following the procedure of Vuister and Bax (1993). ${ }^{3} \mathrm{~J}_{\mathrm{HNCH} \alpha}$ coupling constants were also measured for hCPEBpep2 using the $2 \mathrm{D}{ }^{1} \mathrm{H}-{ }^{1} \mathrm{H}$ COSY spectrum. Utilizing the Karplus equation, (Karplus, 1963), these ${ }^{3} \mathrm{~J}_{\mathrm{HNCH} \alpha}$ coupling constants can be related at the backbone $\phi$ angle, which is different for $\alpha$-helical, statistical coil and $\beta$-strands.

Relaxation: To assess the dynamics on the ps-ns time scales, the heteronuclear ${ }^{15} \mathrm{~N}\left\{{ }^{1} \mathrm{H}\right\}$ NOE (hNOE) of backbone amide groups was registered as the ratio of spectra recorded with and without saturation in an interleaved mode. Long recycling delays of $13 \mathrm{~s}$ were used. Two sets of experiments, one at $25^{\circ} \mathrm{C}$ and one at $5{ }^{\circ} \mathrm{C}$ were recorded at $800 \mathrm{MHz}$. Uncertainties in peak integrals were determined from the standard deviation of intensities from spectral regions devoid of signal which contain only noise.

In addition, $\mathrm{R}_{1} \rho$ relaxation rates, which are sensitive to the presence of preferred, rigid conformers on slower $\mu$ s-ms timescales were measured by recording two sets of ten ${ }^{1} \mathrm{H}-{ }^{15} \mathrm{~N}$ correlation spectra with relaxation delays at 8, 300, 36, 76, 900, 100, 500, 156, 200 and $700 \mathrm{~ms}$. One set of experiments was recorded at $25{ }^{\circ} \mathrm{C}$ and the second was recorded at $5{ }^{\circ} \mathrm{C}$. The relaxation rates were calculated by least-squares fitting of an exponential decay function to the data using NMRPipe (Delagio et al., 1995). As an additional check, the data were also analyzed independently by using the program DynamicsCenter 2.5.2 (Bruker Biospin).

\section{Results}

hCPEB3's IDR is chiefly disordered. As a first step to experimentally characterize hCPEB3's IDR, we probed the complete 426 residue IDR of hCPEB3 by biophysical techniques and homonuclear NMR. Its fluorescence emission spectra, recorded at temperatures ranging from 2 to $70{ }^{\circ} \mathrm{C}$, show emission maximum $>350 \mathrm{~nm}$. This is consistent with its six Trp residues being solvent exposed and not buried in the hydrophobic core of a folded domain (Sup. Fig. 1A) (Alston et al., 2004). The far UV CD spectrum of the hCPEB3 IDR also shows the hallmarks of a disordered protein, namely a minimum near $200 \mathrm{~nm}$ (Denning et al., 2003). No spectral features indicative of $\alpha$-helix and $\beta$-sheet; namely, minima at 208, 218 or $222 \mathrm{~nm}$ and no maximum at 195 $\mathrm{nm}$, are evident (Sup. Fig. 1B). The $1 \mathrm{D}{ }^{1} \mathrm{H}$ and $2 \mathrm{D}{ }^{1} \mathrm{H}-{ }^{1} \mathrm{H}$ NOESY spectra show ${ }^{1} \mathrm{H}$ signals clustered into a narrow bands near the values observed for unstructured short peptides (Sup Fig. 1C) (Bundi \& Wüthrich, 1979; López-Alonso et al., 2010). The sequence alignment of several representative vertebrate CPEB3 proteins using the TCoffee program is shown in Sup. Fig. 2. Very similar results were obtained from the Omega Clustal program (not shown). Whereas most IDPs show poor levels of sequence conservation, some stretches rich in hydrophobic residues, such residues M1-T12, W111F139 and Y341-I357, are highly conserved. By contrast, glutamine rich, alanine rich and 
some proline rich segments are present only in mammals. Taking all these data together, the presence of large, stably folded domains in the IDR can be ruled out, but short segments with partly populated secondary structures could still be present.

Atomic level characterization reveals partially structured elements in hCPEB's Nterminal "disordered" region. To discover and characterize possible segments with partial secondary structure, we applied multidimensional heteronuclear NMR. As the full length IDR is too long to characterize by this methodology, we have followed the "divide and conquer" approach developed by Zweckstetter et al. to characterize tau, a similarly sized IDP implicated in Alzheimer's disease and other tauopathies (Mukrasch et al., 2009). As described in the Material \& Methods section, and shown in Fig. 1, eight overlapping segments of 100 residues were characterized.

Using our powerful ${ }^{13} \mathrm{CO},{ }^{15} \mathrm{~N},{ }^{1} \mathrm{HN}$ based assignment strategy, over $99 \%$ of the main chain ${ }^{13} \mathrm{CO},{ }^{13} \mathrm{C} \alpha,{ }^{15} \mathrm{~N},{ }^{1} \mathrm{HN}$ and the ${ }^{13} \mathrm{C} \beta$ resonances were assigned for residues $1-$ 450 of hCPEB3. The assigned $2 \mathrm{D}{ }^{1} \mathrm{H}^{-15} \mathrm{~N}$ HSQC and $2 \mathrm{D}{ }^{13} \mathrm{CO}^{15} \mathrm{~N}$ spectra of segment 4 are shown in Sup. Fig. 3 and Sup. Fig. 4, respectively. The chemical shifts of the complete IDR of hCPEB 3 are reported in the BMRB (entry number 50256). Multiple attempts to express and purify hCPEB3 segment 2, which spans residues 51-150, by recombinant methods were unsuccessful. Nevertheless, all the residues within segment 2 are present and have been characterized structurally in the context of segments 1 and 3 . To test if there might be some structure in the neighborhood of residues 90-110 which corresponds to the middle of segment 2 and the C- and N-termini of segments 1 and 3, respectively, we studied the conformation of a twenty residue peptide corresponding to residues 91 - 110 of hCPEB3 by NMR spectroscopy. No significant trends towards structure formation were detected (Sup. Fig. 5).

The first residues of hCPEB3 adopt a partly populated $\alpha$-helix which precedes the Q-rich stretch. The conformational chemical shifts point to the formation of partly populated $\alpha$-helix in the first ten residues of the protein (Figure $\mathbf{2 A , B}$ ). Increased conformational chemical shifts are observed at $5{ }^{\circ} \mathrm{C}$, reflecting a higher amount of helical structure upon cooling. Relaxation measurements detect that these residues are the most rigid part of segment 1 (Figure $\mathbf{2} \mathbf{C , D}$ ).

The helix detected for these first residues extends N-terminally into the His/Tev tag. Although the presence of this tag does not appear to increase the population of helical structures in the other segments studied, to rule out a possible structure-promoting effect on segment 1 , we tried to remove it by proteolytic cleavage with the TEV protease. Multiple attempts failed, which suggests that the helix spanning the last residues of His/Tev tag and the first residues of the hCPEB3 IDR is present and impedes the proteolytic cleavage. Therefore, we characterized a dodecamer peptide whose sequence corresponds to the first twelve residues: $\mathrm{M}_{1}$ QDDLLMDKSKT $_{12}$, of the hCPEB3 IDR. The observation of a series of weak ${ }^{1} \mathrm{HN}_{\mathrm{i}}-{ }^{1} \mathrm{HN}_{\mathrm{i}+1}$ nuclear Overhauser enhancement (NOE) crosspeaks reveals that this peptide has a slight tendency to form $\alpha$-helix in aqueous buffer (Sup. Fig. 6A). Fluorinated alcohols like trifluoroethanol (TFE) and 
hexafluoroisopropanol (HFIP) are known to increase the population of helical conformations in peptides which have an $\alpha$-helix forming tendency, but not in peptides which prefer to adopt $\beta$-strands or random coil (Muñoz et al., 1995). In the presence of $20 \%$ HFIP, the population of helix in this peptide increases strongly, based on the observation of stronger and more numerous NOE crosspeaks as well as ${ }^{1} \mathrm{H} \alpha$ and ${ }^{13} \mathrm{C} \alpha$ conformational chemical shifts (Sup. Fig. 6B). These findings confirm that the first 12 residues of hCPEB3 do tend to adopt an $\alpha$-helix.

Interestingly enough, the polyQ segment, $\mathrm{Q}_{16} \mathrm{QQQRQQQQ}{ }_{24}$, does not form an $\alpha$-helix or a $\beta$-strand and appears to be thoroughly disordered and flexible (Figure 2A,B). This polyQ segment is preceded and followed by Pro-Gln-Pro residue triplets $\left(\mathrm{P}_{13} \mathrm{QP}_{15}\right.$ and $\mathrm{P}_{25} \mathrm{QP}_{27}$ ). Considering the inhibitory effect of proline residues previously observed for polyQ amyloid formation in Huntingtin by Wetzel and co-workers (Bhattacharyya et al., 2006), it is likely that these PQP mini-motifs check amyloidogenesis by the polyQ segment. The first 100 residues also contain a predicted SUMOylation site (Ramírez de Mingo et al., 2020) at Lys 47 and ends with a proline-rich segment $\mathrm{P}_{86} \mathrm{PQQPPPPQEPAAPG}_{100}$, which is associated with solubility. Whereas recently reported NMR criteria (Treviño et al., 2018), allow us to rule out that this stretch folds into a stable polyproline II (PPII) helical bundle, residues 86-93 adopt an isolated, partly populated PPII helix (Figure 2E). In fact, the consecutive proline residues show a distinct pattern of conformational chemical shifts; namely $+0.6 \mathrm{ppm},-1.0$ and -0.3 for ${ }^{13} \mathrm{C} \alpha,{ }^{13} \mathrm{C} \beta$ and ${ }^{13} \mathrm{CO}$, respectively (Sup. Fig. 7). Not observed in isolated proline residues, we advance that they are hallmarks of a PPII helical conformation.

Residues 101 - 200 of hCPEB3 contains a rigid nonpolar segment and a PPII helix. Regarding residues $101-200$, no strong trends to adopt $\alpha$-helical or $\beta$-structures are detected. Nevertheless, the stretch composed of residues, $\mathrm{W}_{111}$ STGTTNAVEDSFFQGITPVNGTMLFQNF $_{139}$ which contain numerous aliphatic and aromatic residues, shows relatively high rigidity, both on fast ns/ps as well as slower $\mu \mathrm{s} / \mathrm{ms}$ timescales (Sup. Fig. 8). This finding is interesting considering that this segment also appears to be essential for hCPEB3 amyloid formation in vitro (Ramírez de Mingo et al., 2020). In addition, the stretch of residues 161-190:

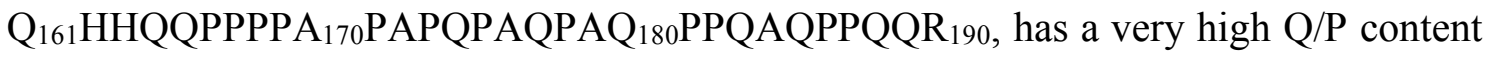
and Pro and Gln are the residues with the highest intrinsic tendencies to adopt PPII helices (Kelly et al., 2001). The consecutive proline residues, $\mathrm{P}_{166} \mathrm{PPPAPAPQP}_{175}$, also display the characteristic PPII pattern of conformational chemical shifts (Sup. Fig. 7) seen for residues 86-93. We hypothesize that these segments may bind profilin, which has specific domains to interact with proline-rich polypeptides (Metzler et al., 1994) and to mediate interactions with the actin, whose levels rise at the synapse following CPEB3 aggregation (Stephan et al., 2015).

Residues 201-300 contain three $\alpha$-helical segments and a disordered (VG)5 segment. Upon observing significant chemical shift deviations with respect to values predicted for a statistical coil, we utilized the programs TALOS+ and CYANA to calculate a family 
for conformers for residues $\underline{\text { A202 }}_{20 R S A A A Y}{ }_{210}$ GHQPIMTSKP $_{220-}$ $\underline{S}_{221} \underline{\operatorname{SSSAVAAAA}}_{230} \underline{\mathrm{AAAAASSASS}}_{240} \underline{\mathrm{SWNTHQSVHAA}}_{250}$ (Figure 3A). The three segments of underlined residues have been detected to adopt partially populated $\alpha$ helices. Based on the magnitude of the conformational chemical shifts, the helical populations are different; being about $30 \%$ for the $\mathrm{A}_{202}-\mathrm{Y}_{210} \alpha$-helix, $80 \%$ for the $\mathrm{S}_{222-}$ $\mathrm{A}_{234} \alpha$-helix and $20 \%$ for the $\mathrm{A}_{238}-\mathrm{Q}_{246} \alpha$-helix at $5{ }^{\circ} \mathrm{C}$; these populations decrease but are still significant at $25^{\circ} \mathrm{C}$ (Figure 3B). The presence of the first and second helices are confirmed by ${ }^{1} \mathrm{HN}-{ }^{1} \mathrm{H} \alpha$ coupling constants (Sup. Fig. 9). The helices are not especially rigid on fast ps-ns time scales (Figure 3C) or the slower $\mu$ s-ms time domain (Figure 3D) at $25^{\circ} \mathrm{C}$, but do show a heightened stiffness at $5{ }^{\circ} \mathrm{C}$ (Sup. Fig. 8). Helical wheel projections (Sup. Fig. 10) suggest that different stabilizing interactions contribute to these helices. Gly 211 and His 212 are positioned to stabilize the $\mathrm{A}_{202}-\mathrm{Y}_{210} \alpha$-helix by a Ccapping motif (Aurora \& Rosa, 1998). Whereas Ala has a very high intrinsic helix forming propensity, the propensity of Ser is low (Chakrabartty et al., 1994). In this segment, however, the Ser residues are positioned at the N-terminus of the $\alpha$-helices, where adding negative charge via phosphorylation would increase the helical population, considering the well-known stabilizing effects of charge / macrodipole interactions and $\mathrm{N}$-capping H-bonds (Chakrabartty \& Baldwin 1995). The last $\alpha$-helix is less populated, but its stability would be increased if W242 were to engage in long-range interactions.

One of the most striking features in hCPEB3's sequence is a short dipeptide protein motif (Val-Gly) 5 spanning residues 271 - 281, which is reminiscent of longer $(\text { Ala-Gly) })_{\mathrm{N}}$ and (Pro-Gly) $)_{\mathrm{N}}$ and (Arg-Gly) $)_{\mathrm{N}}$ dipeptide repeat proteins encoded by mutant C9orf72 which have been implicated in ALS (Morón-Oset et al., 2019); (Mizielinska et al., 2014). Our in silico analysis identified this segment as having a high potential to form amyloid (Ramírez de Mingo et al., 2020). In the context of hCPEB3, however, this segment is among the most disordered and flexible of all the zones of the protein. We speculate that these exposed and flexible Val residues may be poised to interact with a still unidentified factor through the formation of hydrophobic interactions.

Just beyond the (VG) 5 segment, there is a stretch of 15 residues: $\mathrm{S}_{284}$ PLNPISPLKKPFSS 298 , whose NMR parameters indicate disorder and flexibility (Sup. Tables 1, 2). Nevertheless, this stretch contains four Ser residues reported to phosphorylated by protein kinase A (PKA) or calcium/calmodulin-dependent protein kinase II (Kaczmarczyk et al., 2016) (Table 1), and therefore might be important for the transition between short- and long-term memory. Residues P $_{303}$-PKFPRAAP 311 are proline rich. Predictions suggest that Arg 308 can be methylated (Table 1). This modification has been reported to fortify cation $-\pi$ interactions, reduce interactions with RNA and destabilize condensates in other proteins (Chong et al., 2018).

\section{The residues forming the NES show a marked tendency to adopt $\alpha$-helical} structures. Significant conformational chemical shifts were also observed for residues L349-L353 which form the NES (Figure 1, Figure 4, below), indicating the presence of helical structure. Using the ${ }^{13} \mathrm{CO},{ }^{15} \mathrm{~N},{ }^{1} \mathrm{HN},{ }^{13} \mathrm{C} \alpha$ and ${ }^{13} \mathrm{C} \beta$ chemical shift data as input, a family of conformers was calculated using the programs TALOS + and CYANA for 
residues P333-P363. This 31-residue segment is rich in aromatic (five) and aliphatic (six) residues, which is unusual for a disordered polypeptide. The resulting structures reveal that residues L346-L349 adopt one turn of $\alpha$-helix and residues S352-M356 form a short $\alpha$-helix (Figure 4A). The family of calculated conformations shows a high structural similarity in the helical regions (residues L346 - M356) with an RMSD of $0.9 \AA$ for the backbone and $1.6 \AA$ for all heavy atoms. It is notable that this conformer positions five nonpolar residues: L346, L349, L353, M354 and I357 on the same face of the $\alpha$-helices. Y341, the putative phosphorylation site, is in an extended portion of the backbone and would be accessible for this PTM. Whereas the conformational ensemble will contain many other structures, based on conformational chemical shifts as illustrated by the $\Delta \delta^{13} \mathrm{C} \alpha \& \Delta \delta^{13} \mathrm{CO}$ values shown in Fig. 4B the $\alpha$-helical population is about one third. The presence of rigid conformers is corroborated by relatively high $\left\{{ }^{1} \mathrm{H}\right\}-{ }^{15} \mathrm{~N}$ NOE ratios (Fig 4C) and elevated transverse relaxation ratios (Fig. 4D).

Beyond the NES $\alpha$-helix, no segments with preferred secondary structure are detected. The last residues of the segment 8 construct: $\mathrm{S}_{426}$ RKVFVGGLPPDIDEDEITASFRRF 450 , belong to the RRM1 domain. According to the 3D structure (Tsuda et al., 2014) residues K428-G432 adopt a $\beta$-strand and residues E440-R449 form an $\alpha$-helix in the context of the complete RRM1 domain. Here these segments appear to be largely disordered. After a proline-rich zone ending around residue 380, the next fifty residues have a higher content of nonpolar residues and tend to be more rigid (Sup. Fig 8). Residues 400 - 412: SHGDQALSSGLSS contain five Ser residues reported to be phosphorylated (Kaczmarczyk et al., 2016, Table 1). Like the four Ser residues of the 284-291 stretch mentioned above, this could be an element involved in the structural basis of memory consolidation.

\section{Discussion}

The biophysical analysis of the full length IDR of hCPEB3 shows that it lacks stable secondary structure. Compared to well-ordered protein domains, disordered regions tend to change their amino acid sequence much more rapidly over the course of evolution due to a lack of structural constraints for folding (Brown et al., 2002). In hCPEB3, the Nterminal $\alpha$-helix and the 350's (NES) $\alpha$-helix as well as its accompanying putative phosphoTyr site, are well conserved throughout vertebrate CPEB3's, which strongly suggests that they are important for biological function (Sup. Fig. 2). Additional segments, like the stretch of hydrophobic residues key for amyloid formation (Ramírez del Mingo et al., 2020) and a cluster of three Trp residues (W242, W252 and W259) are also strictly conserved from mammals to fish. In contrast, the Gln-rich segment at the Nterminus, the Pro-rich 'breaker' regions and the Ala-rich helices are well conserved in mammals but not across all vertebrates. In some lower vertebrates, there is an alternative Q-rich region positioned after the 100's hydrophobic segment. The relatively rapid evolution of these elements could be related to the development of the mammalian brain as compared to those of lower vertebrates. By contrast, the ability to move the polyQ 
segment or substitute it for hydrophobic amyloidogenic segment and still retain function highlights the cassette or modular nature of PLDs which was previously established for the Drosophila homolog, Orb2A (Hervás et al., 2016).

Over the past decade, the PLD of several proteins involved in transcription regulation and/or RNA metabolism have been characterized. Some of these, including Huntingtin (Jayaraman et al., 2012), the Androgen Receptor (Eftekharzaedeh et al., 2016), Ataxin-7 (Hong et al., 2019) and TDP-43 (Lim et al., 2016) (Table 2) have a hydrophobic, helix-forming segment which precedes the $\mathrm{Q}$ - or $\mathrm{Q} / \mathrm{N}$-rich amyloid-forming segment. These hydrophobic helices have been proposed to promote intermolecular associations, either through the formation of coiled-coils (Pelassa et al., 2014) or by forming biomolecular condensates via liquid-liquid phase separation (Conicella et al., 2016). In the case of Huntingtin, the polyQ segment is followed by a stretch of polyproline, which will be locked in a PPII helical conformation. This polyP stretch has been shown to strongly slow Huntingtin amyloid formation in vitro (Bhattacharyya et al., 2006).

PPII helices may regulate amyloid formation and mediate interactions with actin. It is important to point out that whereas hCPEB3 and its homologs Orb2 and ApCPEB have helix destabilizing residues between the N-terminal helix and the amyloidogenic Q-rich segment, such as proline in hCPEB3 and Orb2A or serine and valine in the case of $A p C P E B$, no such helix busters are present in the analogous segments of Huntingtin, the Androgen Receptor or TDP-43 (Table 2). The absence of these breakers allows the polyQ segment to interact with the helix through the formation of sidechain to main chain hydrogen bonds in the case of the Androgen Receptor (Escobedo et al., 2019) and to initiate as well as to form part of the amyloid structure as proposed recently for TDP-43 by Eisenberg and collaborators (Cao et al., 2019). Based on these observations, we propose that the presence of helix breakers between the helix and the polyQ(/N) segments in functional amyloids and their absence in pathological amyloids is a fundamental difference that could be a molecular basis of their radically different toxicities.

PPII helices, well known in collagen and certain glycine-rich proteins (Pentelute et al., 2008), also play key roles in mediating protein-protein interactions in biomolecular condensates (Guo et al., 2019). Whereas conformation chemical shifts have proven to be extremely useful tools to identify $\alpha$-helices and $\beta$-strands in folded and disordered proteins, conformational chemical shifts for PPII helices were unknown. The first 450 residues of hCPEB3 include no less than 66 proline residues (15\% of the total). On the basis of the thorough set of chemical shifts obtained here, including Pro ${ }^{15} \mathrm{~N}$ assignments which are rare in the literature, we propose a pattern of conformational chemical shifts that define PPII helices (Table 3). Combined with the recently published standards for glycine-rich PPII helical bundles (Treviño et al., 2018), these values should aid the detection of PPII helices in biomolecular condensates and the elucidation of their roles in physiology and pathology. 
$\alpha$-Helices are stabilized by distinct interactions in pathological and functional amyloids. The disposition of the side chains in the N-terminal $\alpha$-helices of TDP-43 and CPEB homologs is shown in Sup. Fig. 10. TDP-43's $\alpha$-helix is almost six turns long. The first three are stabilized by numerous Ala and Met residues, which have a high intrinsic helix forming propensity. Most hydrophobic residues are clustered on the nonpolar face of the helix. In contrast, Trp334 is exposed on the polar face. This Trp is known to mediate intermolecular contacts which drive liquid/liquid phase separation (Li et al., 2018). The $\alpha$-helix of ApCPEB is composed of four turns; the first two have a well defined hydrophobic face while the third and fourth are more polar. Leu and Asn are known to contribute stability and specificity to interhelical contacts in coiled-coils (Oakley and Kim, 1998). Orb2's putative $\alpha$-helix is shorter with only three turns and may be less stable based on its content of four Asn and one Val residues, which have poor intrinsic helix propensities. It is amphiphilic with well defined polar and nonpolar faces. Phe 5 lies at the center of the hydrophobic face. This residue has been shown to be essential for proper amyloid formation and memory consolidation (Majumdar et al., 2012). Interestingly enough, some residues following the poly- $Q$ segment of Orb2;

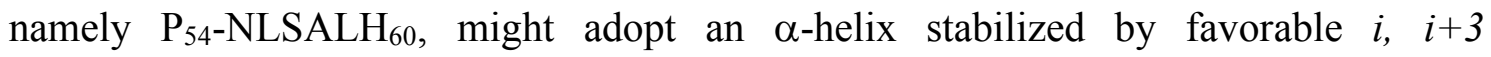
hydrophobic interactions (L58-L61), N-capping (P56, N57) and charge (H62) / helix macrodipole interactions (Chakrabartty \& Baldwin, 1995).

The first 30 residues of CPEB3 are very well conserved in mammals and rather well conserved between mammals and reptiles, which speaks to their functional relevance (Sup. Fig. 2). The N-terminal helix of hCPEB3 is composed of residues whose intrinsic helix propensities are significantly lower than those of TDP-43. This suggests that longrange interactions might be necessary for it to become fully populated. Most of the hydrophobic residues of hCPEB3 are clustered on one side of the helix, to form a nonpolar face. The exception is Met 7, which is on the hydrophilic face. Such exceptionally exposed hydrophobic residues, like Trp 334 in TDP-43 (Cao et al., 2019), and perhaps Trp 242 in the hCPEB3 $\mathrm{A}_{238}-\mathrm{Q}_{246} \alpha$-helix, often mediate long-range interactions.

STAT5B binding may occlude hCPEB's NES leading to nuclear retention. The calculated conformers for the NES showed the preferred formation of $\alpha$-helices which orient five hydrophobic residues on the same side (Fig. 4); this is a common feature on NES (Xu et al., 2012). CPEB3 constantly shuttles in and out of the nucleus and its subcellular localization has important consequences as it regulates gene transcription via association with STAT5B in the nuclei of neurons as well as mRNA translation in dendritic spines. Previous studies reported that neural stimulation leads to hCPEB3, which is normally predominately cytoplasmic, to be concentrated in the nucleus. An earlier study (Peng et al., 2010) revealed that the region spanning residues $639-700$ of STAT5B binds the N-terminal IDR of hCPEB3. To learn about the nature of this interaction, we examined the recently elucidated structure of STAT5B (PDB: 6MBW), (de Araujo ED et al., 2017). Remarkably, this structure reveals that the key hCPEB3interacting residues in STAT5B form an SH2 domain. Based on this, we advance that hCPEB3 may contain a phospho-Tyr residue that is recognized and bound tightly by 
STAT5B. Considering the results of previously reported very thorough motif analyses (Liu et al., 2010 \& Corwin et al., 2017), the most promising site for phospho-Tyr modification in hCPEB3 is Tyr341, as this residue is bordered by SRPY ${ }_{341}$ DTF which closely matches a consensus substrate "[E/V/D]-[G]-[I/P/L]-Y-E-X-[F/T/V]" of Scr, which is one of the most relevant tyrosine kinases. Based on this proposed PTM site, and our finding that the preferred conformation of the nearby NES (L349-L353) is an $\alpha$-helix (vide supra), we can advance a working hypothesis to account for how STAT5B binding retains hCPEB3 in the nucleus; namely binding of phospho-Tyr341 by the $\mathrm{SH} 2$ domain of STAT5B would occlude the neighboring NES of hCPEB3. This would explain why hCPEB3 becomes concentrated in the nucleus under conditions of neuronal stimulation (Chao et al., 2012). Recent studies have shown that certain mutations in the nuclear localization and export signals or defects in nucleocytoplasmic transport of TDP-43, another aggregation-prone, RNA-binding protein, lead to an aberrant aggregation (Gasset-Rosa et al., 2019). Based on this, we propose that mutations in the NES of hCPEB3 (residues L346-M356) would likely disrupt transport and lead to memory and learning defects.

\section{Towards an atomic-level understanding of the role of hCPEB3 in memory} consolidation. By combining the results obtained here with observations that residues 1-250 are necessary and sufficient for amyloid formation in vitro (Ramírez de Mingo et al., 2020), we advance a working hypothesis for hCPEB3 conformational changes during memory consolidation (Figure 5). It is supported by analogous results on Aplysia CPEB (Raveendrea et al., 2013) and polyalanine expansions (Polling et al., 2015), which led to the proposal of similar mechanisms. Initially, the first 250 residues of CPEB3, which are known to be necessary and sufficient for aggregation and amyloid formation (Fioriti et al., 2015; Ramírez de Mingo et al., 2020), are mostly disordered except for the relatively stable $\alpha$-helices formed by residues $222-234$ and modestly populated $\alpha$-helices at the $\mathrm{N}$ terminus and spanning residues 202-212 and 237-245 (Fig. 5A). The $\mathrm{Q}_{4} \mathrm{RQ}_{4}$ motif and hydrophobic segment $\mathbf{F}_{\mathbf{1 2 3}} \mathbf{F Q G I T - P V N G T - M L F Q N F} \mathbf{F}_{139}$ are initially disordered and premature amyloidogenesis is discouraged by SUMOlyation (Drisaldi et al., 2015) and proline breaker motifs.

Following deSUMOlyation and other putative PTMs such as phosphorylation, association among the $\alpha$-helices would become possible, and might be strengthened by hydrophobic interactions between Met 7 and Trp 242 or cation- $\pi$ interactions between Lys 11 and Trp 242 (Fig. 5B). The increased production of hCPEB3 upon neuronal stimulation (Fioriti et al., 2015) as well as the proximity of the alanine rich $\alpha$-helix (residues 222-234) may promote $\alpha$-helix formation by the QQQQRQQQQ motif. These could then associate to form a coiled-coil, as has been demonstrated in model polypeptides (Fiumara et al., 2010; Pelassa et al., 2014).

These events would reinforce intermolecular contacts within the dendritic P-body like granule (Ford et al., 2019) leading to gelification and, eventually, amyloid formation (Fig. 5C). The final amyloid structure could be comprised of the $\mathrm{Q}_{4} \mathrm{RQ} \mathrm{Q}_{4}$ motif and the hydrophobic segment. In addition, the polyA segment of helices 202-212 and 222-234 
may also transform into amyloid (Fig. 5D). Such $\alpha$-helix to amyloid conformational transformations have been previously described in alanine-rich polypeptides as diverse as a fish antifreeze protein (Graether et al., 2003) and a synthetic (Ala) ${ }_{10}$-(His) 6 hexadecapeptide (Hamley et al., 2014), and could form pathological amyloids in a number of reported diseases involving expansion of polyAla tracts (Albrecht \& Mundlos 2005).

Residues 217-284 of CPEB3 have been reported to be key for interactions with actin (Stephan et al., 2015). Considering this, the hypothetical associations among the $\alpha-$ helices formed by residues $\mathrm{M}_{1}-\mathrm{T}_{12}$ and residues $\mathrm{A}_{202}-\mathrm{Q}_{246}$ advanced in the preceding paragraphs could dispose the PPII helices formed by residues $\mathrm{P}_{86}-\mathrm{Q}_{94}$ and $\mathrm{P}_{116}-\mathrm{A}_{170}$ to bind profilin. This protein contains a second binding site specific for actin and promotes the formation of actin filament networks (Ferron et al., 2007). Such actin networks are known to become more extensive and robust as a dendritic bud strengthens during memory consolidation (Basu \& Lamprecht, 2018).

Acknowledgements: This study was supported by projects SAF2016-76678-C2-1-R (MC-V) and SAF2016-76678-C2-2-R (DVL) from the Spanish Ministry of Economy and Competitivity. NMR experiments were performed in the "Manuel Rico" NMR Laboratory (LMR) of the Spanish National Research Council (CSIC), a node of the Spanish Large-Scale National Facility (ICTS R-LRB). We are grateful to Dr. Miguel Mompeán and Dr. Javier Oroz for critical comments on the manuscript.

Author Contributions: 1. Funding: MC-V \& DVL; 2. Research planning \& design: DRdM, RH, DP-U, MC-V and DVL. 3. Cloning, sample production and purification: DRdM \& RH; 4. Data acquisition: DP-U \& DVL; 5. Data analysis: DP-U, DRdM \& DVL; 6. Writing: DRdM \& DVL. All authors carefully read the MS, provided corrections and approved the final version of the MS.

\section{References}

Albrecht, A., \& Mundlos, S. (2005). The other trinucleotide repeat: polyalanine expansion disorders. Current opinion in Genetics \& Development, 15(3), 285-293. https://doi.org/10.1016/j.gde.2005.04.003

Alston, R. W., Urbanikova, L., Sevcik, J., Lasagna, M., Reinhart, G. D., Scholtz, J. M., \& Pace, C. N. (2004). Contribution of single tryptophan residues to the fluorescence and stability of ribonuclease Sa. Biophys. J., 87(6), 4036-4047. https://doi.org/10.1529/biophysj.104.050377

Aurora, R. \& Rose, G. D. (1998). Helix capping. Prot. Sci. 7: 21-38.

Basu, S., \& Lamprecht, R. (2018). The Role of Actin Cytoskeleton in Dendritic Spines in the Maintenance of Long-Term Memory. Frontiers in Molecular Neuroscience, 11, 143. https://doi.org/10.3389/fnmol.2018.00143 
Brown, C. J., Takayama, S., Campen, A. M., Vise, P., Marshall, T. W., Oldfield, C. J., Williams, C. J., \& Dunker, A. K. (2002). Evolutionary rate heterogeneity in proteins with long disordered regions. Journal of Molecular Evolution, 55(1), 104-110. https://doi.org/10.1007/s00239-001-2309-6

Bhattacharyya, A., Thakur, A. K., Chellgren, V. M., Thiagarajan, G., Williams, A. D., Chellgren, B. W., Creamer, T. P., \& Wetzel, R. (2006). Oligoproline effects on polyglutamine conformation and aggregation. J. Mol. Biol., 355(3), 524-535. https://doi.org/10.1016/j.jmb.2005.10.053

Bundi, A., \& Wüthrich, K. (1979) ${ }^{1} \mathrm{H}-\mathrm{NMR}$ parameters of the common amino acid residues measured in aqueous solution of the linear tetrapeptides H-Gly-Gly-X-L-Ala-OH. Biopolymers 18(2), 285-297.

Cao Q, Boyer DR, Sawaya MR, Ge P, Eisenberg DS. Cryo-EM structures of four polymorphic TDP-43 amyloid cores. Nat Struct Mol Biol. 2019 26(7):619-627. doi: 10.1038/s41594-019-0248-4.

Chakrabartty A, Baldwin RL. Stability of alpha-helices. Adv Protein Chem. $1995 ; 46,141-76$.

Chakrabartty, A., Kortemme, T., \& Baldwin, R.L. Helix propensities of the amino acids measured in alanine-based peptides without helix-stabilizing side-chain interactions. Protein Sci. 1994 3(5), 843-52.

Chao HW, Lai YT, Lu YL, Lin CL, Mai W, \& Huang YS. NMDAR signaling facilitates the IPO5-mediated nuclear import of CPEB3. Nucleic Acids Res. 2012 40(17), 8484-98.

Choi, Y. B., Kadakkuzha, B. M., Liu, X. A., Akhmedov, K., Kandel, E. R., \& Puthanveettil, S. V. (2014). Huntingtin is critical both pre- and postsynaptically for long-term learning-related synaptic plasticity in Aplysia. PLoS One, 9(7), e103004. https://doi.org/10.1371/journal.pone.0103004

Chong, P. A., Vernon, R. M., \& Forman-Kay, J. D. (2018). RGG/RG Motif Regions in RNA Binding and Phase Separation. Journal of Molecular Biology, 430(23), 4650-4665. https://doi.org/10.1016/j.jmb.2018.06.014

Conicella, A. E., Zerze, G. H., Mittal, J., \& Fawzi, N. L. (2016). ALS Mutations Disrupt Phase Separation Mediated by $\alpha$-Helical Structure in the TDP-43 Low-Complexity C-Terminal Domain. Structure (London, England : 1993), 24(9), 1537-1549. https://doi.org/10.1016/j.str.2016.07.007

Corwin, T., Woodsmith, J., Apelt, F., Fontaine, J. F., Meierhofer, D., Helmuth, J., Grossmann, A., AndradeNavarro, M. A., Ballif, B. A., \& Stelzl, U. (2017). Defining human tyrosine kinase phosphorylation networks using yeast as an in vivo model substrate. Cell Sstems, 5(2), 128-139.e4. https://doi.org/10.1016/j.cels.2017.08.001

Cougot, N., Bhattacharyya, S. N., Tapia-Arancibia, L., Bordonné, R., Filipowicz, W., Bertrand, E., \& Rage, F. (2008). Dendrites of mammalian neurons contain specialized P-body-like structures that respond to neuronal activation. The Journal of 28(51), 13793-13804. https://doi.org/10.1523/JNEUROSCI.415508.2008

Crick F. (1984). Memory and molecular turnover. Nature, 312(5990), 101. https://doi.org/10.1038/312101a0

de Araujo, E. D., Erdogan, F., Neubauer, H. A., Meneksedag-Erol, D., Manaswiyoungkul, P., Eram, M. S., Seo, H. S., Qadree, A. K., Israelian, J., Orlova, A., Suske, T., Pham, H., Boersma, A., Tangermann, S., Kenner, L., Rülicke, T., Dong, A., Ravichandran, M., Brown, P. J., Audette, G. F., ... Gunning, P. T. (2019). Structural and functional consequences of the STAT5B ${ }^{\mathrm{N} 642 \mathrm{H}}$ driver mutation. Nature Comm, 10(1), 2517. https://doi.org/10.1038/s41467-019-10422-7

Delaglio, F., Grzesiek, S., Vuister, G. W., Zhu, G., Pfeifer, J., \& Bax, A. (1995). NMRPipe: a multidimensional spectral processing system based on UNIX pipes. Journal of Biomol NMR, 6(3), 277293. https://doi.org/10.1007/bf00197809

Denning, D. P., Patel, S. S., Uversky, V., Fink, A. L., \& Rexach, M. (2003). Disorder in the nuclear pore complex: the FG repeat regions of nucleoporins are natively unfolded. Proceedings of the National 
Academy of Sciences of the United States of America, 100(5), 2450-2455. https://doi.org/10.1073/pnas.0437902100

Diez-García, F., Gómez-Pinto, I., Chakrabartty, A., González, C., \& Laurents, D. V. (2012). Conformation specificity and arene binding in a peptide composed only of Lys, Ile, Ala and Gly. European Biophysics Journal 41(1), 63-72. https://doi.org/10.1007/s00249-011-0758-4

Di Tommaso, P., Moretti, S., Xenarios, I., Orobitg, M., Montanyola, A., Chang, J. M., Taly, J. F., \& Notredame, C. (2011). T-Coffee: a web server for the multiple sequence alignment of protein and RNA sequences using structural information and homology extension. Nucleic Acids Research, 39(Web Server issue), W13-W17. https://doi.org/10.1093/nar/gkr245

Drisaldi B, Colnaghi L, Fioriti L, Rao N, Myers C, Snyder AM, Metzger DJ,Tarasoff J, Konstantinov E, Fraser PE, Manley JL, Kandel ER. SUMOylation Is an Inhibitory Constraint that Regulates the Prion-like Aggregation and Activity of CPEB3. Cell Rep. 2015. 11(11), 1694-702. doi: 10.1016/j.celrep.2015.04.061

Eftekharzadeh, B., Piai, A., Chiesa, G., Mungianu, D., García, J., Pierattelli, R., Felli, I. C., \& Salvatella, X. (2016). Sequence Context Influences the Structure and Aggregation Behavior of a PolyQ Tract. Biophysical J.110(11), 2361-2366. https://doi.org/10.1016/j.bpj.2016.04.022

Escobedo A, Topal B, Kunze MBA, Aranda J, Chiesa G, Mungianu D, Bernardo-Seisdedos G, Eftekharzadeh B, Gairí M, Pierattelli R, Felli IC, Diercks T, Millet O, García J, Orozco M, Crehuet R, Lindorff-Larsen K, Salvatella X. Side chain to main chain hydrogen bonds stabilize a polyglutamine helix in a transcription factor. Nat Commun. 2019, 10(1): 2034. doi:10.1038/s41467-019-09923-2.

Ferron, F., Rebowski, G., Lee, S. H., \& Dominguez, R. (2007). Structural basis for the recruitment of profilin-actin complexes during filament elongation by Ena/VASP. The EMBO Journal, 26(21), 45974606. https://doi.org/10.1038/sj.emboj.7601874

Fioriti, L., Myers, C., Huang, Y. Y., Li, X., Stephan, J. S., Trifilieff, P., Colnaghi, L., Kosmidis, S., Drisaldi, B., Pavlopoulos, E., \& Kandel, E. R. (2015). The persistence of hippocampal-based memory requires protein synthesis mediated by the prion-like protein CPEB3. Neuron, 86(6), 1433-1448. https://doi.org/10.1016/j.neuron.2015.05.021

Fiumara, F., Fioriti, L., Kandel, E. R., \& Hendrickson, W. A. (2010). Essential role of coiled coils for aggregation and activity of Q/N-rich prions and PolyQ proteins. Cell, 143(7), 1121-1135. https://doi.org/10.1016/j.cell.2010.11.042

Fiumara, F., Rajasethupathy, P., Antonov, I., Kosmidis, S., Sossin, W. S., \& Kandel, E. R. (2015). MicroRNA-22 gates long-term heterosynaptic plasticity in Aplysia through presynaptic regulation of CPEB and downstream targets. Cell Reports, 11(12), 1866-1875. https://doi.org/10.1016/j.celrep.2015.05.034

Ford, L., Ling, E., Kandel, E.R., \& Fioriti, L. CPEB3 inhibits translation of mRNA targets by localizing them to P bodies. Proc Natl Acad Sci USA. 2019 116(36), 18078-18087. doi: 10.1073/pnas.1815275116),

Gasset-Rosa, F., Lu, S., Yu, H., Chen, C., Melamed, Z., Guo, L., Shorter, J., Da Cruz, S., \& Cleveland, D. W. (2019). Cytoplasmic TDP-43 de-mixing independent of stress granules drives inhibition of nuclear import, Loss of nuclear TDP-43, and cell death. Neuron, 102(2), 339-357.e7. https://doi.org/10.1016/j.neuron.2019.02.038

Gill, J., Park, Y., McGinnis, J. P., Perez-Sanchez, C., Blanchette, M., \& Si, K. (2017). Regulated intron removal integrates motivational state and experience. Cell, 169(5), 836-848.e15. https://doi.org/10.1016/j.cell.2017.05.006

Graether, S. P., Slupsky, C. M., \& Sykes, B. D. (2003). Freezing of a fish antifreeze protein results in amyloid fibril formation. Biophysical J., 84(1), 552-557. https://doi.org/10.1016/S0006-3495(03)74874-7

Güntert, P., \& Buchner, L. (2015) Combined automated NOE assignment and structure calculation with CYANA. J. Biomol. NMR, 62, 453-471. 
Guo, Y. E., Manteiga, J. C., Henninger, J. E., Sabari, B. R., Dall'Agnese, A., Hannett, N. M., Spille, J. H., Afeyan, L. K., Zamudio, A. V., Shrinivas, K., Abraham, B. J., Boija, A., Decker, T. M., Rimel, J. K., Fant, C. B., Lee, T. I., Cisse, I. I., Sharp, P. A., Taatjes, D. J., \& Young, R. A. (2019). Pol II phosphorylation regulates a switch between transcriptional and splicing condensates. Nature, 572(7770), 543-548. https://doi.org/10.1038/s41586-019-1464-0

Hamley, I. W., Kirkham, S., Dehsorkhi, A., Castelletto, V., Adamcik, J., Mezzenga, R., Ruokolainen, J., Mazzuca, C., Gatto, E., Venanzi, M., Placidi, E., Bilalis, P., \& Iatrou, H. (2014). Self-assembly of a model peptide incorporating a hexa-histidine sequence attached to an oligo-alanine sequence, and binding to gold NTA/nickel nanoparticles. Biomacromolecules, 15(9), 3412-3420. https://doi.org/10.1021/bm500950c

Hervás, R., Li, L., Majumdar, A., Fernández-Ramírez, M., Unruh, J. R., Slaughter, B. D., Galera-Prat, A., Santana, E., Suzuki, M., Nagai, Y., Bruix, M., Casas-Tintó, S., Menéndez, M., Laurents, D. V., Si, K., \& Carrión-Vázquez, M. (2016). Molecular basis of Orb2 amyloidogenesis and blockade of memory consolidation. PLoS biology, 14(1), e1002361. https://doi.org/10.1371/journal.pbio.1002361

Hervas, R., Rau, M. J., Park, Y., Zhang, W., Murzin, A. G., Fitzpatrick, J., Scheres, S., \& Si, K. (2020). Cryo-EM structure of a neuronal functional amyloid implicated in memory persistence in Drosophila. Science 367(6483), 1230-1234. https://doi.org/10.1126/science.aba3526

Hong JY, Wang DD, Xue W, Yue HW, Yang H, Jiang LL, Wang WN, Hu HY. Structural and dynamic studies reveal that the Ala-rich region of ataxin-7 initiates $\alpha$-helix formation of the polyQ tract but suppresses its aggregation. Sci Rep. 2019; 9(1), 7481. doi: 10.1038/s41598-019-43926-9.

Huang YS, Kan MC, Lin CL, Richter JD. CPEB3 and CPEB4 in neurons: analysis of RNA-binding specificity and translational control of AMPA receptor GluR2 mRNA. EMBO J. 2006 25(20), 4865-76.).

Huang, W. H., Chao, H. W., Tsai, L. Y., Chung, M. H., \& Huang, Y. S. (2014). Elevated activation of CaMKII $\alpha$ in the CPEB3-knockout hippocampus impairs a specific form of NMDAR-dependent synaptic depotentiation. Frontiers in Cellular Neuroscience, 8, 367. https://doi.org/10.3389/fncel.2014.00367

Hyman S. E. (2005). Addiction: a disease of learning and memory. The American Journal of Psychiatry, 162(8), 1414-1422. https://doi.org/10.1176/appi.ajp.162.8.1414

Jayaraman, M., Kodali, R., Sahoo, B., Thakur, A. K., Mayasundari, A., Mishra, R., Peterson, C. B., \& Wetzel, R. (2012). Slow amyloid nucleation via $\alpha$-helix-rich oligomeric intermediates in short polyglutamine-containing huntingtin fragments. Journal of Molecular Biology, 415(5), 881-899. https://doi.org/10.1016/j.jmb.2011.12.010

Kaczmarczyk, L., Labrie-Dion, É., Sehgal, K., Sylvester, M., Skubal, M., Josten, M., Steinhäuser, C., De Koninck, P., \& Theis, M. (2016). New phosphospecific antibody reveals isoform-specific phosphorylation of CPEB3 protein. PloS One, 11(2), e0150000. https://doi.org/10.1371/journal.pone.0150000

Kandel ER, Dudai Y, Mayford MR (2014) The molecular and systems biology of memory. Cell, 157: 163186

Karplus, M., (1963). Vicinal proton coupling in nuclear magnetic resonance. J. Am. Chem. Soc. 85(18), 2870-2871. Doi. 10.1021/ja00901a059.

Kelly, M. A., Chellgren, B. W., Rucker, A. L., Troutman, J. M., Fried, M. G., Miller, A. F., \& Creamer, T. P. (2001). Host-guest study of left-handed polyproline II helix formation. Biochemistry, 40(48), 1437614383. https://doi.org/10.1021/bi011043a

Khan, M. R., Li, L., Pérez-Sánchez, C., Saraf, A., Florens, L., Slaughter, B. D., Unruh, J. R., \& Si, K. (2015). Amyloidogenic oligomerization transforms Drosophila Orb2 from a translation repressor to an activator. Cell, 163(6), 1468-1483. https://doi.org/10.1016/j.cell.2015.11.020

Kjaergaard, M. \& Poulsen, F.M. (2011) Sequence correction of random coil chemical shifts: correlations between neighbor correction factors and changes in the Ramachandran distribution J. Biomol. NMR 50(2), $157-165$ 
Kjaergaard, M., Brander, S. \& Poulsen, F.M. (2011) Random coil chemical shifts for intrinsically disordered proteins: Effects of temperature and pH. J. Biomol. NMR 49(2),139-49.

Li HR, Chiang WC, Chou PC, Wang WJ, Huang JR. TAR DNA-binding protein 43 (TDP-43) liquid-liquid phase separation is mediated by just a few aromatic residues. J. Biol. Chem. 2018; 293(16), 6090-6098. doi:10.1074/jbc.AC117.001037

Lim, L., Wei, Y., Lu, Y., \& Song, J. (2016). ALS-Causing Mutations Significantly Perturb the SelfAssembly and interaction with nucleic acid of the intrinsically disordered prion-like domain of TDP43. PLoS Biology, 14(1), e1002338. https://doi.org/10.1371/journal.pbio.1002338

Liu, B. A., Jablonowski, K., Shah, E. E., Engelmann, B. W., Jones, R. B., \& Nash, P. D. (2010). SH2 domains recognize contextual peptide sequence information to determine selectivity. Molecular \& Cellular Proteomics: 9(11) 2391-2404. https://doi.org/10.1074/mcp.M110.001586

López-Alonso, J. P., Bruix, M., Font, J., Ribó, M., Vilanova, M., Jiménez, M. A., Santoro, J., González, C., \& Laurents, D. V. (2010). NMR spectroscopy reveals that RNase A is chiefly denatured in $40 \%$ acetic acid: implications for oligomer formation by 3D domain swapping. Journal of the American Chemical Society, 132(5), 1621-1630. https://doi.org/10.1021/ja9081638

Mackenzie, I. R., Rademakers, R., \& Neumann, M. (2010). TDP-43 and FUS in amyotrophic lateral sclerosis and frontotemporal dementia. The Lancet. Neurology, 9(10), 995-1007. https://doi.org/10.1016/S1474-4422(10)70195-2

Majumdar, A., Cesario, W.C., White-Grindley, E., Jiang, H., Ren, R, Khan, M. R., Li. L., Choi, E. M. K., Kannan, K., Guo, F., Unruh, J., Slaughter, B., \& Si, K. Critical role of amyloid-like oligomers of Drosophila Orb2 in the persistence of memory. Cell. 2012;148(3), 515-529. doi:10.1016/j.cell.2012.01.004

Markley, J. L., Bax, A., Arata, Y., Hilbers, C. W., Kaptein, R., Sykes, B. D., Wright, P. E., \& Wüthrich, K. (1998). Recommendations for the presentation of NMR structures of proteins and nucleic acids--IUPACIUBMB-IUPAB Inter-Union Task Group on the standardization of data bases of protein and nucleic acid structures determined by NMR spectroscopy. European Journal of Biochemistry, 256(1) , 1-15. https://doi.org/10.1046/j.1432-1327.1998.2560001.x

Marley, J., Lu, M., \& Bracken, C. (2001). A method for efficient isotopic labeling of recombinant proteins. Journal of Biomolecular NMR, 20(1), 71-75. https://doi.org/10.1023/a:1011254402785

Metzler, W. J., Bell, A. J., Ernst, E., Lavoie, T. B., \& Mueller, L. (1994). Identification of the poly-Lproline-binding site on human profilin. The Journal of biological chemistry, 269(6), 4620-4625.

Mizielinska, S., Grönke, S., Niccoli, T., Ridler, C. E., Clayton, E. L., Devoy, A., Moens, T., Norona, F. E., Woollacott, I., Pietrzyk, J., Cleverley, K., Nicoll, A. J., Pickering-Brown, S., Dols, J., Cabecinha, M., Hendrich, O., Fratta, P., Fisher, E., Partridge, L., \& Isaacs, A. M. (2014). C9orf72 repeat expansions cause neurodegeneration in Drosophila through arginine-rich proteins. Science 345(6201), 1192-1194. https://doi.org/10.1126/science. 1256800

Morón-Oset, J., Supèr, T., Esser, J., Isaacs, A. M., Grönke, S., \& Partridge, L. (2019). Glycine-alanine dipeptide repeats spread rapidly in a repeat length- and age-dependent manner in the fly brain. Acta Neuropathologica Communications, 7(1), 209. https://doi.org/10.1186/s40478-019-0860-x

Mukrasch, M.D., Bibow, S., Korukottu, J., Jeganathan, S., Biernat, J., Griesinger, C., Mandelkow, E., \& Zweckstetter, M. Structural polymorphism of 441-residue tau at single residue resolution. PLoS Biol. 2009 7(2): e34. doi:10.1371/journal.pbio.1000034.

Muñoz, V., Serrano, L., Jiménez, M. A., \& Rico, M. (1995). Structural analysis of peptides encompassing all alpha-helices of three alpha/beta parallel proteins: Che-Y, flavodoxin and P21-ras: implications for alpha-helix stability and the folding of alpha/beta parallel proteins. Journal of Molecular Biology, 247(4), 648-669. https://doi.org/10.1016/s0022-2836(05)80145-7 
Nallamsetty, S., Kapust, R. B., Tözsér, J., Cherry, S., Tropea, J. E., Copeland, T. D., \& Waugh, D. S. (2004). Efficient site-specific processing of fusion proteins by tobacco vein mottling virus protease in vivo and in vitro.Protein expression and purification, 38(1), 108-115. https://doi.org/10.1016/j.pep.2004.08.016

Nelson, P. T., Dickson, D. W., Trojanowski, J. Q., Jack, C. R., Boyle, P. A., Arfanakis, K., Rademakers, R., Alafuzoff, I., Attems, J., Brayne, C., Coyle-Gilchrist, I., Chui, H. C., Fardo, D. W., Flanagan, M. E., Halliday, G., Hokkanen, S., Hunter, S., Jicha, G. A., Katsumata, Y., Kawas, C. H., ... Schneider, J. A. (2019). Limbic-predominant age-related TDP-43 encephalopathy (LATE): consensus working group report. Brain : A Journal of Neurology, 142(6), 1503-1527. https://doi.org/10.1093/brain/awz099

Oakley, M.G., \& Kim, P.S. A buried polar interaction can direct the relative orientation of helices in a coiled coil. Biochemistry. 1998, 37(36), 12603-12610. doi:10.1021/bi981269m

Pantoja-Uceda, D., \& Santoro, J. (2013). Direct correlation of consecutive C'-N groups in proteins: a method for the assignment of intrinsically disordered proteins. Journal of Biomolecular NMR, 57(1), 5763. https://doi.org/10.1007/s10858-013-9765-3

Pantoja-Uceda, D., \& Santoro, J. (2014). New ${ }^{13}$ C-detected experiments for the assignment of intrinsically disordered proteins. Journal of Biomolecular NMR, 59(1), 43-50. https://doi.org/10.1007/s10858-014$\underline{9827-1}$

Pelassa, I., Corà, D., Cesano, F., Monje, F. J., Montarolo, P. G., \& Fiumara, F. (2014). Association of polyalanine and polyglutamine coiled coils mediates expansion disease-related protein aggregation and dysfunction. Human Molecular Genetics, 23(13), 3402-3420. https://doi.org/10.1093/hmg/ddu049

Peng, S.C., Lai, Y.T., Huang, H.Y., Huang, H. D., \& Huang, Y.S., A novel role of CPEB3 in regulating EGFR gene transcription via association with Stat5b in neurons. Nucleic Acids Res. 2010 38(21): 7446-57. doi: 10.1093/nar/gkq634.).

Pentelute, B. L., Gates, Z. P., Tereshko, V., Dashnau, J. L., Vanderkooi, J. M., Kossiakoff, A. A., \& Kent, S. B. (2008). X-ray structure of snow flea antifreeze protein determined by racemic crystallization of synthetic protein enantiomers. Journal of the American Chemical Society, 130(30), 9695-9701. https://doi.org/10.1021/ja8013538

Polling, S., Ormsby, A. R., Wood, R. J., Lee, K., Shoubridge, C., Hughes, J. N., Thomas, P. Q., Griffin, M. D., Hill, A. F., Bowden, Q., Böcking, T., \& Hatters, D. M. (2015). Polyalanine expansions drive a shift into $\alpha$-helical clusters without amyloid-fibril formation. Nature structural \& molecular biology, 22(12), 10081015. https://doi.org/10.1038/nsmb.3127

Ramírez de Mingo D, López-García P, Laurents DV, Carrión-Vázquez M (2020) “Molecular forces governing hCPEB3 liquid demixing and amyloidogenesis”. Submitted.

Raveendra, B. L., Siemer, A. B., Puthanveettil, S. V., Hendrickson, W. A., Kandel, E. R., \& McDermott, A. E. (2013). Characterization of prion-like conformational changes of the neuronal isoform of Aplysia CPEB. Nature Structural \& Molecular Biology, 20(4), 495-501. https://doi.org/10.1038/nsmb.2503

Salehi-Ashtiani, K., Lupták, A., Litovchick, A., \& Szostak, J. W. (2006). A genomewide search for ribozymes reveals an HDV-like sequence in the human CPEB3 gene. Science 313(5794), 1788-1792. https://doi.org/10.1126/science. 1129308

Si, K., Lindquist, S., \& Kandel, E.R. A neuronal isoform of the Aplysia CPEB has prion-like properties. Cell. 2003 115(7), 879-91

Si, K., \& Kandel, E.R. The role of functional prion-like proteins in the persistence of memory. Cold Spring Harb Perspect Biol. 2016 8(4), a021774. doi: 10.1101/cshperspect.a021774

Sievers, F., Wilm, A., Dineen, D., Gibson, T. J., Karplus, K., Li, W., Lopez, R., McWilliam, H., Remmert, M., Söding, J., Thompson, J. D., \& Higgins, D. G. (2011). Fast, scalable generation of high-quality protein 
bioRxiv preprint doi: https://doi.org/10.1101/2020.05.12.091587; this version posted May 14,2020 . The copyright holder for this preprint (which was not certified by peer review) is the author/funder, who has granted bioRxiv a license to display the preprint in perpetuity. It is made available under aCC-BY-NC-ND 4.0 International license.

multiple sequence alignments using Clustal Omega.Molecular Systems Biology, 7, 539. https://doi.org/10.1038/msb.2011.75

Spera, S., \& Bax, A. (1991) Empirical corrleation between protein backbone conformation and Calpha and Cbeta 13C NMR chemical shifts. J. Am. Chem. Soc. 113(14): 5490-5492. doi.10.1021/ja00014a071

Stephan, J.S., Fioriti, L., Lamba, N., Colnaghi, L., Karl, K., Derkatch, I.L., \& Kandel, ER, The CPEB3 Protein Is a Functional Prion that Interacts with the Actin Cytoskeleton. Cell Rep. 2015, 11(11), 1772-1785.

Sun, Z. Y., Frueh, D. P., Selenko, P., Hoch, J. C., \& Wagner, G. (2005). Fast assignment of 15N-HSQC peaks using high-resolution 3D HNcocaNH experiments with non-uniform sampling. Journal of Biomolecular NMR, 33(1), 43-50. https://doi.org/10.1007/s10858-005-1284-4

Terlau, H., \& Seifert, W. (1990). Fibroblast growth factor enhances long-term potentiation in the hippocampal slice. The European Journal of Neuroscience, 2(11), 973-977. https://doi.org/10.1111/j.1460-9568.1990.tb00009.x

Treviño, M. Á., Pantoja-Uceda, D., Menéndez, M., Gomez, M. V., Mompeán, M., \& Laurents, D. V. (2018). The singular NMR fingerprint of a polyproline II helical bundle. Journal of the American Chemical Society, 140(49), 16988-17000. https://doi.org/10.1021/jacs.8b05261

Tsuda, K., Kuwasako, K., Nagata, T., Takahashi, M., Kigawa, T., Kobayashi, N., Güntert, P., Shirouzu, M., Yokoyama, S., Muto, Y. Novel RNA recognition motif domain in the cytoplasmic polyadenylation element binding protein 3. Proteins 2014 82(10), 2879-86. doi: 10.1002/prot.24651.

Vogler, C., Spalek, K., Aerni, A., Demougin, P., Müller, A., Huynh, K.D., Papassotiropoulos, A., de Quervain, D.J. CPEB3 is associated with human episodic memory. Front Behav Neurosci. 2009 3:4. doi: 10.3389/neuro.08.004.2009

Vuister, G. W., Bax, A., Quantitative J correlation: a new approach for measuring homonuclear J(HN-Ha) coupling constants in 15N-enriched proteins. J. Am. Chem. Soc. 1993, 115, 7772-7777.

Wang, Y., and Jardetzky, O. (2002) Probability-based protein secondary structure identification using combined NMR chemical shift data. Prot. Sci. 11: 842-861

Wishart, D. S., \& Sykes, B. D. (1994). The ${ }^{13} \mathrm{C}$ chemical-shift index: a simple method for the identification of protein secondary structure using ${ }^{13} \mathrm{C}$ chemical-shift data. Journal of Biomolecular NMR, 4(2), 171-180. https://doi.org/10.1007/bf00175245

Xu, D., Farmer, A., Collett, G., Grishin, N. V., \& Chook, Y. M. (2012). Sequence and structural analyses of nuclear export signals in the NESdb database. Molecular Biology of the Cell, 23(18), 3677-3693. https://doi.org/10.1091/mbc.E12-01-0046 
Table 1: Sequence of the disordered N-terminal region of hCPEB3

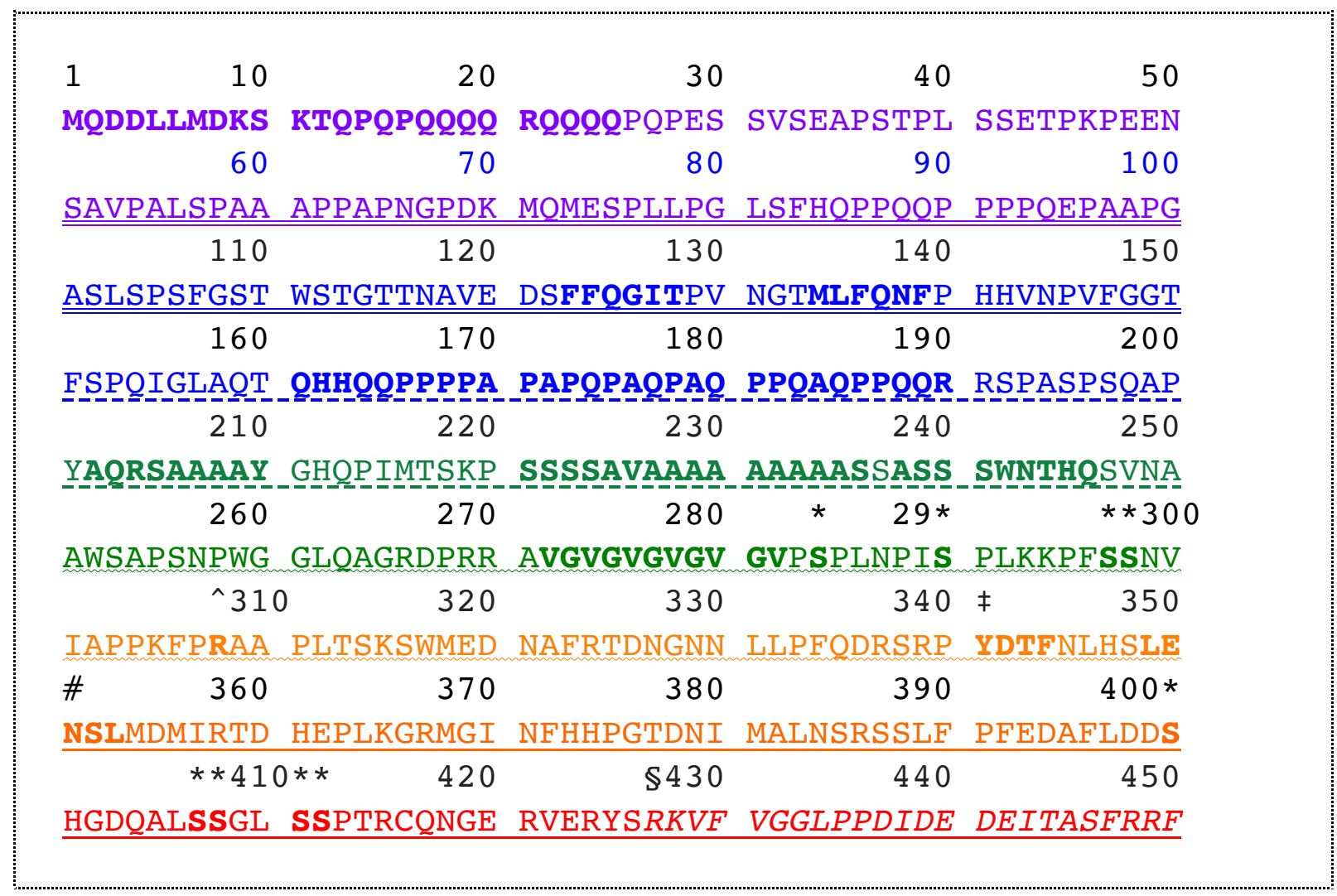

Segment 1 spans hCPEB3 residues 1-100 and is colored purple residues;

segment 2, residues $51-150$ (double underlined residues);

segment 3, residues $101-200$ (blue residues);

segment 4, residues $151-250$ (dashed underlined residues);

segment 5, residues $201-300$ (green residues);

segment 6 , residues 251 - 350, (wavy underlined residues);

segment 7 , residues $302-400$ (orange residues) and finally

segment 8 , which is composed of residues $352-450$ (single underlined residues).

Residues of structural or functional interest are in bold font.

${ }^{\wedge}$ The putative dimethyl-Arg site (R308).

*The putative phosphoTyr site, Y341 putatively recognized by STAT5B's SH2 domain.

\#The nuclear export signal, L349-L353

*Putative phosphorylation sites: S284, S290, S297, S298, S400, S407, S408, S411 and S412.

$\S$ Residues belonging to the first RRM1 domain are written in italics. 
Table 2: Hydrophobic helices and Pro rich stretches modulate amyloid formation by Q-, Q/N-rich segments.

\begin{tabular}{|c|c|}
\hline PROTEIN & SEQUENCE* \\
\hline Huntingtin & $\begin{array}{l}M_{\odot 01} A T L E K L M K A \\
\text { FESLKSFQQQ QQQQQQQQQQ QQQQQQQQPP PPPPPPPPQ LPQPPPQAQP }\end{array}$ \\
\hline ANDROGEN RCPT & Ho41PEAASAAPP GASLLLLQQ QQQQQQQQQQ QQQQQQQQQQ ETSPRQQQQ QGEDGSPQAH \\
\hline TDP-43 & P ${ }_{319}$ AMMAAAQAA LQSSWGMMGM LASQQNQSGP SGNNQNQGNM QREPNQAFGS FNNSYSSINI \\
\hline Ataxin-7 & 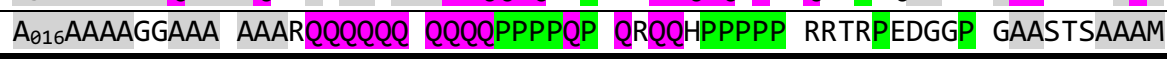 \\
\hline hCPEB3 & MøO1QDDLLMDKS KTQPQPQQQQ QRQQQQPQPE SSVSEAPSTP LSSETPKPEE NSALPALSPA \\
\hline $\begin{array}{l}\text { Drosophila } \\
\text { Orb2A }\end{array}$ & 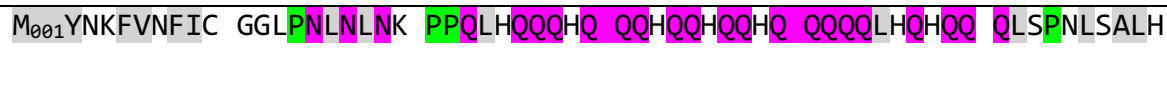 \\
\hline Aplysia CPEB & FөзeEIFRRINAL LDNSLEANNV SCSQ \\
\hline
\end{tabular}

* In these sequences, nonpolar residues are shaded gray, Gln and Asn residues are shaded magenta and Prolines are shaded green. 


\section{Table 3:}

Conformational Chemical Shifts for $\alpha$-helices, $\beta$-strands and PPII helices.

\begin{tabular}{|c|c|c|c|c|}
\hline & $\alpha$-helix & $\beta$-strand & $\begin{array}{c}\text { Gly-rich } \\
\text { PPII helical bundle }\end{array}$ & $\begin{array}{c}\text { Isolated Pro-rich } \\
\text { PPII helix }\end{array}$ \\
\hline$\delta \Delta^{13} \mathrm{C} \alpha$ & $3.1^{\mathrm{a}} / 2.9^{\mathrm{b}}$ & $-1.5^{\mathrm{a}} /-1.8^{\mathrm{b}}$ & $-0.6^{\mathrm{d}}$ & $+0.6^{\mathrm{e}}$ \\
\hline$\delta \Delta^{13} \mathrm{C} \beta$ & $-0.4^{\mathrm{a}} /-0.8^{\mathrm{b}}$ & $+2.2^{\mathrm{a}} /+2.7^{\mathrm{b}}$ & $+0.3^{\mathrm{d}}$ & $-1.0^{\mathrm{e}}$ \\
\hline$\delta \Delta^{13} \mathrm{CO}$ & $2.2^{\mathrm{c}} / 2.2^{\mathrm{b}}$ & $-2.2^{\mathrm{c}} /-2.1^{\mathrm{b}}$ & $-0.2^{\mathrm{d}}$ & $-0.3^{\mathrm{e}}$ \\
\hline
\end{tabular}
a. from Spera \& Bax (1991)
b. from Wang and Jardetzky (2002) for alanine.
c. calculated from Wishart \& Skyes (1994)
d. from Treviño et al. (2018)
e. This study. 
Figure 1. Domain Structure and Activities of CPEB3
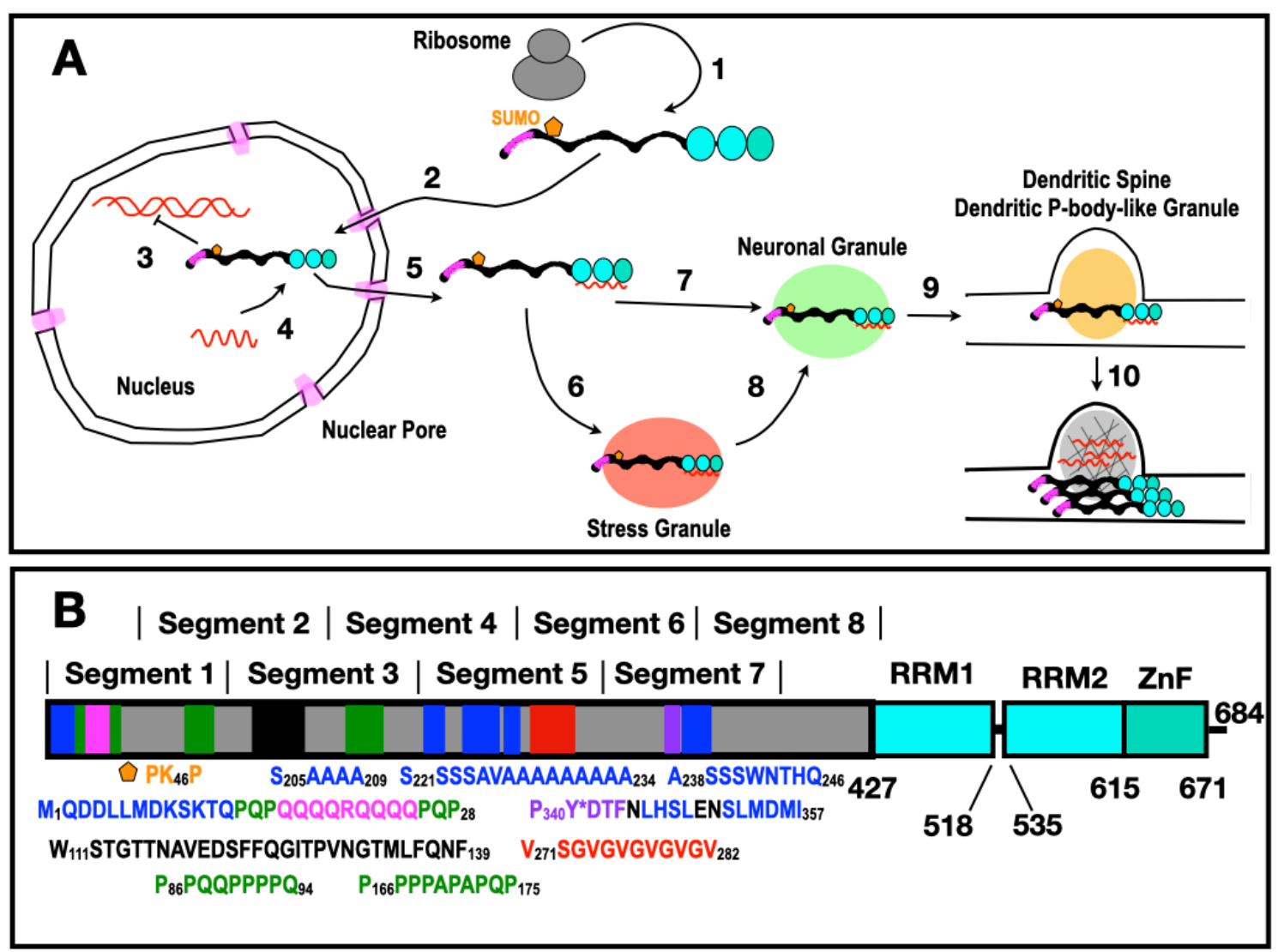

A. CPEB3 is present in multiple cellular compartments. Dendritic stimulation leads to temporary, phosphorylation-mediated short term memory and 1 . increased synthesis of the protein CPEB3. Composed of an N-terminal disordered region (black) which includes a Q-rich segment necessary for functional aggregation (magenta), hCPEB3 also contains RRM domains (cyan) and a ZZ-Zinc finger domain (turquoise). 2. Upon continued neuro-stimulation, CPEB3 enters the nucleus through the nuclear pore (light magenta), which is a macromolecular condensate. Once in the nucleus, CPEB3 indirectly regulates transcription through STAT5B 3, and binds to certain mRNAs 4 (red). This binding suppresses translation. After exiting the nucleus through the nuclear pore, 6 CPEB3+mRNA may associate with a stress granule (rose) during moments of cellular stress. In the absence of stress (7) or its passing (8), CPEB3+mRNA will combine with another condensate called neuronal granules (light green) for transport to dendritic spines (9), where CPEB3+mRNA associate with still another class of condensate called a dendritic P-bodylike structure (golden) (Cougot et al., 2008). Further neuronal stimulation (10) causes synapse-specific deSUMOlyation, CPEB3 aggregation and translational activation of previously repressed mRNA, leading to morphological changes and fortification of the spine, which is proposed to be the basis of long-term memory. This is a simplified model based on (Kandel et al., 2014).

B. CPEB3 domain composition and its N-terminal intrinsically disordered domain (gray) contains key elements with preferred conformers colored blue for $\alpha$-helix, magenta for polar amyloidogenic, black for hydrophobic amyloidogenic, green for PPII helix, purple for the putative phosphoTyr site, and red for highly disordered segments. The two RRM domain are colored cyan and the C-terminal Zinc Finger is shown in turquoise. 
Figure 2: The N-terminal 25 residues of hCPEB3 adopt a hydrophobic $\alpha$-helix followed by a disordered polyQ segment flanked by PQP mini-breaker motifs.
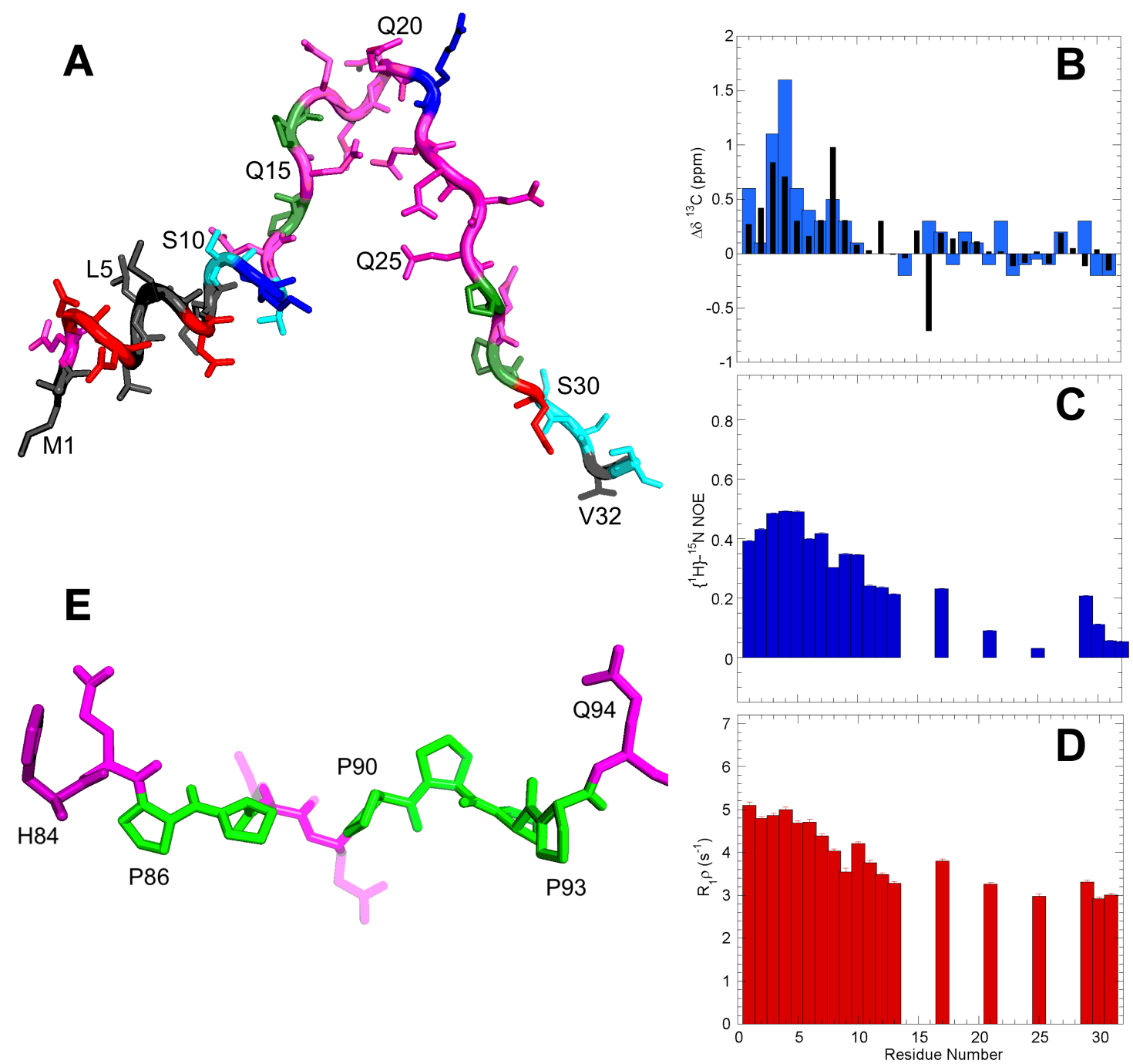

The N-terminus of hCPEB3 contain helix-forming and an amyloidogeneic $\mathrm{Q}_{4} \mathrm{RQ}_{4}$ segments, which are separated by PQP mini breaker motifs. A representative conformers (A) of the first 32 residues from a family of 20 structures calculated using the program CYANA based on TALOS+ backbone angle restrictions derived from chemical shift data. Nonpolar residues are colored black, aromatics=purple, $\mathrm{Q} / \mathrm{N}=$ magenta, $\mathrm{E} / \mathrm{D}=$ red, $\mathrm{K} / \mathrm{R}=$ blue, $\mathrm{G}=$ green, $\mathrm{C}, \mathrm{S}, \mathrm{T}=$ cyan. Note that whereas this conformer shows an $\alpha$-helix at the N-terminus, fully disordered species dominant the conformation ensemble, as the (B) ${ }^{13} \mathrm{C} \alpha$ (blue) and ${ }^{13} \mathrm{CO}$ (black) conformational chemical shifts indicate a $15-20 \%$ population of helix at 25 ${ }^{\circ}$ C. (C) $\left\{{ }^{1} \mathrm{H}\right\}-{ }^{15} \mathrm{~N}$ NOE and (D) $\mathrm{R}_{1} \rho$ relaxation measurements indicate that this helical conformation is less mobile than the polyQ segment at $\mathrm{ns} / \mathrm{ps}$ and $\mu \mathrm{s} / \mathrm{ms}$ timescales, respectively at $25^{\circ} \mathrm{C}$. Error bars are shown in panels (C) and (D) but are small as the estimated uncertainties are $<0.01$ for the hNOE and $<0.1 \mathrm{~s}^{-1}$ for $\mathrm{R}_{1} \rho$. Missing values in panels $\mathbf{C}$ and $\mathbf{D}$ are due to overlap of ${ }^{1} \mathrm{H}^{15} \mathrm{~N}$ peaks or a lack of ${ }^{1} \mathrm{H}^{15} \mathrm{~N}$ signals in the case of proline residues. (E) Representative structure, from a family of 20 CYANA conformers, of the proline rich segment, H84-Q94, featuring a PPII helix that spans residues P86-Q94. Residues are colored as in panel $\mathbf{A}$. 
Figure 3. Residues $201-250$ adopt three $\alpha$-helices.
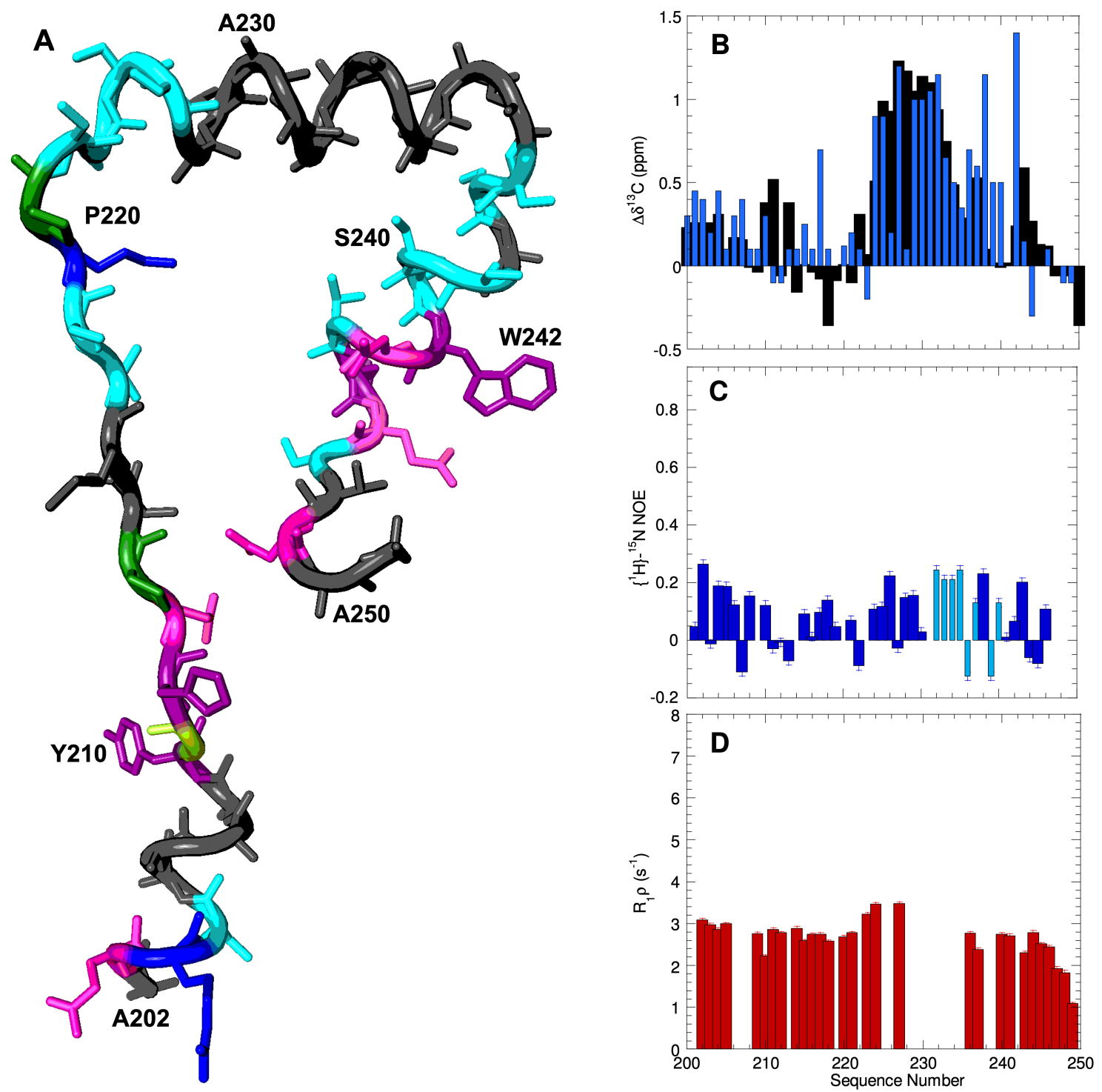

A. Representative conformer of residues 201-250, showing three alpha helices. As in Figure 2. Nonpolar residues are colored black, aromatics=purple, $\mathrm{Q} / \mathrm{N}=$ magenta, $\mathrm{E} / \mathrm{D}=\mathrm{red}, \mathrm{K} / \mathrm{R}=\mathrm{blue}, \mathrm{G}=$ green, $\mathrm{C}, \mathrm{S}, \mathrm{T}=$ cyan.

B. ${ }^{13} \mathrm{CO}$ (black) and ${ }^{13} \mathrm{C} \alpha$ (blue) conformational chemical shifts of residues $201-250$ at $25^{\circ} \mathrm{C}$. Note that the second $\alpha$-helix which contains nine consecutive Ala residues has a relatively high helical population. C. $\left\{{ }^{1} \mathrm{H}\right\}{ }^{15} \mathrm{~N}$ NOE ratios. Values shown in dark blue are of individual ${ }^{1} \mathrm{H}^{15} \mathrm{~N}$ resonances; those in light blue correspond to overlapped peaks.

D. $R_{1 \rho}$ values reveal the $\mathrm{ps} / \mathrm{ns}$ and $\mathrm{ms} / \mathrm{ms}$ time scales. Significantly higher $\left\{{ }^{1} \mathrm{H}\right\}-{ }^{15} \mathrm{~N}$ NOE ratios and $\mathrm{R}_{1 \rho}$ values are observed for these residues at $5{ }^{\circ} \mathrm{C}$ (Sup. Fig. 8). 
Figure 4. Conformation of the NES and nearby phospho-Tyr site.
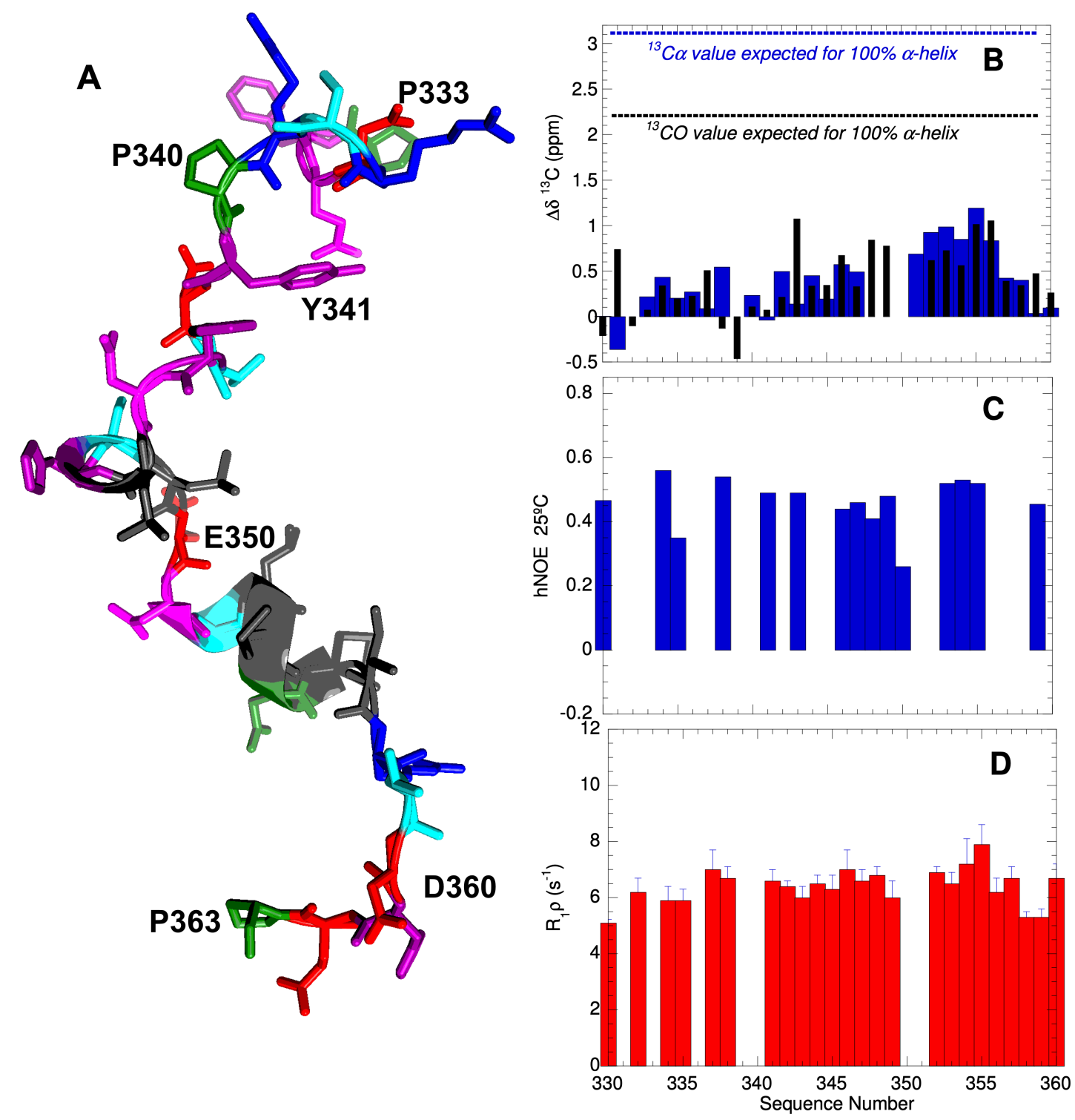

A. Representative conformer of $\mathrm{P}_{333} \mathrm{FQDRSRP}_{340} \mathrm{YDTFNLHSLE}_{350} \mathrm{NSLMDMIRTD}_{360} \mathrm{HEP}_{363}$ shown with cationic residues $(\mathrm{R} \& \mathrm{~K})$ colored blue, aromatics $(\mathrm{F}, \mathrm{Y} \& \mathrm{H})=$ purple, anionic $(\mathrm{E} \& \mathrm{D})=$ red, aliphatic $(\mathrm{I}, \mathrm{L}, \mathrm{M})=$ dark gray, amyloidogenic $(\mathrm{N} \& \mathrm{Q})=$ magenta, hydroxyl bearing $(\mathrm{S} \& \mathrm{~T})=$ cyan, and proline $=$ green. Spiral ribbons mark the helical segments spanning residues $346-349$ and $352-356$. B. Conformational chemical shifts of ${ }^{13} \mathrm{C} \alpha$ (blue bars) and ${ }^{13} \mathrm{CO}$ (black narrow bars) afford detection of helical conformations. C. $\left\{{ }^{1} \mathrm{H}\right\}-{ }^{15} \mathrm{~N}$ NOE ratios of 0.85 and -0.20 are indicative of high rigidity and flexibility, respectively, on ps-ns time scales. D. higher $\mathrm{R}_{2}$ rates are diagnostic of rigidity on $\mu \mathrm{s}-\mathrm{ms}$ time scales. 


\section{Figure 5}

Working Hypothesis for hCPEB3 Structural Changes During Memory Consolidation.

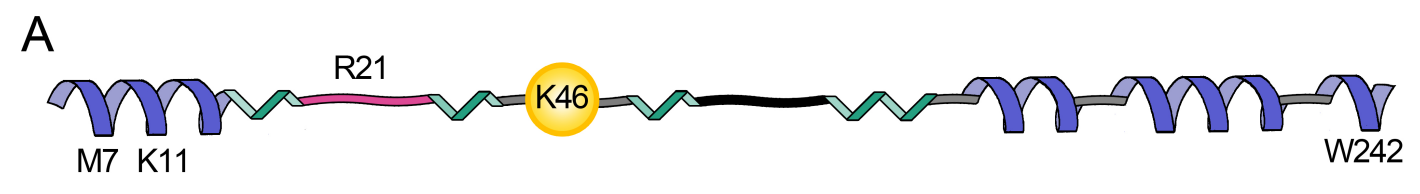

$\mathrm{B}$

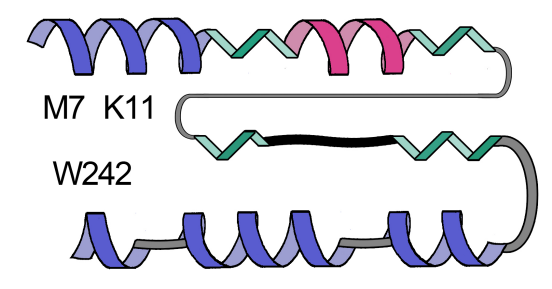

C

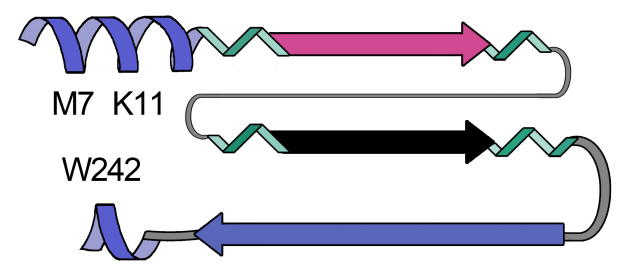

A. The first 250 residues of hCPEB 3 contain $4 \alpha$-helices (blue spirals), the first and third $\alpha$-helices are relatively stable. Proline-rich segments (green) and SUMOylation as putatively to occur at K46 by in silicio methods (Ramírez de Mingo et al., 2020) prevent premature association and amyloid formation by the $\mathrm{Q}_{4} \mathrm{RQ}_{4}$ segment (magenta) and the hydrophobic motif (black squiggle).

B. Following deSUMOlyation and putatively phosphorylation, association between the fourth and first helices could occur, strengthened by hydrophobic and cation- $\pi$ interactions. The $\mathrm{Q}_{4} \mathrm{RQ}_{4}$ segment may adopt an $\alpha$-helix and associate with the Ala rich $\alpha$-helices to form a coiled-coil. The structural transformations may well enhance intermolecular contacts within the dendritic P-body like granule, leading to gelification and eventually, amyloid formation.

C. The final amyloid could be composed of the $\mathrm{Q}_{4} \mathrm{RQ}_{4}$ segment and hydrophobic tract, and possibly the Ala-rich segments. The final configuration of the polyPro segments (green) would promote profilin binding and the initiation of a more robust actin filament network. 
Sup. Table 1: NMR Spectral Parameters

\begin{tabular}{|c|c|c|c|}
\hline Experiment & Number of Scans & Sweep Width (ppm) & Matrix \\
\hline \multicolumn{4}{|c|}{ Segments $1,3,4,5,6,7 \& 8$} \\
\hline $1 \mathrm{D}^{1} \mathrm{H}$ & 8 & 10 & $32 \mathrm{k}$ \\
\hline $2 \mathrm{D}{ }^{1} \mathrm{H}-{ }^{15} \mathrm{~N}$ HSQC & $2-8$ & $10{ }^{1} \mathrm{H} \times 20{ }^{15} \mathrm{~N}$ & $2 \mathrm{k} \times 512$ \\
\hline 2D CON* & $4-16$ & $10{ }^{13} \mathrm{CO} \times 35^{15} \mathrm{~N}$ & $1 \mathrm{k} \times 512$ \\
\hline 3D HNCO & $4-8$ & $10{ }^{1} \mathrm{H} \times 20{ }^{15} \mathrm{~N} \times 10{ }^{13} \mathrm{C}$ & $2 \mathrm{k} \times 64 \times 128$ \\
\hline 3D hacacoNcaNCO* & 8 & $10{ }^{13} \mathrm{CO} \times 35^{15} \mathrm{~N} \times 20{ }^{15} \mathrm{~N}$ & $1 \mathrm{k} \times 48 \times 96$ \\
\hline 3D hacaCOncaNCO* & 8 & $10{ }^{13} \mathrm{CO} \times 35^{15} \mathrm{~N} \times 20{ }^{13} \mathrm{CO}$ & $1 \mathrm{k} \times 48 \times 96$ \\
\hline $3 \mathrm{D} \mathrm{CCCON}{ }^{*}$ & & $\begin{array}{l}10^{13} \mathrm{CO} \times 35^{15} \mathrm{~N} \times 60 \\
{ }^{13} \mathrm{C} \text { (aliphatic) }\end{array}$ & $1 \mathrm{k} \times 56 \times 96$ \\
\hline 3D CBCACON & 8 & $\begin{array}{l}10^{13} \mathrm{CO} \times 35^{15} \mathrm{~N} \times 60 \\
{ }^{13} \mathrm{C} \text { (aliphatic) }\end{array}$ & $1 \mathrm{k} \times 64 \times 80$ \\
\hline $3 \mathrm{D} \mathrm{HNHA}^{\S}$ & 8 & $11^{1} \mathrm{HN} \times 23{ }^{15} \mathrm{~N} \times 11{ }^{1} \mathrm{H} \alpha$ & $2 \mathrm{k} \times 96 \times 48$ \\
\hline \multicolumn{4}{|l|}{ Segments $3,7 \& 8^{\dagger}$} \\
\hline 3D HNcaCO & 16 & $10{ }^{1} \mathrm{H} \times 20{ }^{15} \mathrm{~N} \times 10^{13} \mathrm{C}$ & $2 \mathrm{k} \times 32 \times 64$ \\
\hline 3D hNcocaNH & 12 & $10{ }^{1} \mathrm{H} \times 20{ }^{15} \mathrm{~N} \times 20{ }^{15} \mathrm{~N}$ & $2 \mathrm{k} \times 64 \times 90$ \\
\hline 3D HncocaNH & 12 & $10{ }^{13} \mathrm{CO} \times 20{ }^{15} \mathrm{~N} \times 10^{13} \mathrm{CO}$ & $2 \mathrm{k} \times 96 \times 48$ \\
\hline 3D CBCAcoNH & 16 & $10{ }^{1} \mathrm{H} \times 20{ }^{15} \mathrm{~N} \times 10{ }^{13} \mathrm{C}$ & $2 \mathrm{k} \times 32 \times 64$ \\
\hline \multicolumn{4}{|l|}{ Relaxation } \\
\hline $2 \mathrm{D}\left\{{ }^{1} \mathrm{H}\right\}-{ }^{15} \mathrm{~N} \mathrm{NOE}^{\oplus}$ & $8-16$ & $10^{1} \mathrm{H} \times 20{ }^{15} \mathrm{~N}$ & $2 \mathrm{k} \times 512$ \\
\hline 2D ${ }^{1} \mathrm{H}_{-}{ }^{15} \mathrm{~N} \mathrm{~T} \mathrm{~T}_{1} \rho^{*}$ & $8-16$ & $10{ }^{1} \mathrm{H} \times 20{ }^{15} \mathrm{~N}$ & $2 \mathrm{k} \times 256$ \\
\hline \multicolumn{4}{|l|}{ Peptides $1 \& 2$} \\
\hline 2D ${ }^{1} \mathrm{H}-{ }^{1} \mathrm{H} \mathrm{COSY}$ & 16 & $11 \times 11$ & $2 \mathrm{k} \times 512$ \\
\hline 2D ${ }^{1} \mathrm{H}-{ }^{1} \mathrm{H}$ TOCSY & 8 & $11 \times 11, \mathrm{t}_{\mathrm{mix}}=60 \mathrm{~ms}$ & $2 \mathrm{k} \times 512$ \\
\hline 2D ${ }^{1} \mathrm{H}-{ }^{1} \mathrm{H}$ NOESY & 64 & $11 \mathrm{x} 11, \mathrm{t}_{\mathrm{mix}}=150 \mathrm{~ms}$ & $2 \mathrm{k} \times 512$ \\
\hline 2D ${ }^{1} \mathrm{H}-{ }^{13} \mathrm{C}$ HSQC & 144 & $\begin{array}{l}10 \times 80, \text { recorded in } 100 \% \\
D_{2} \mathrm{O}\end{array}$ & $1 \mathrm{k} \times 128$ \\
\hline $2 \mathrm{D}{ }^{1} \mathrm{H}-{ }^{15} \mathrm{~N}$ HSQC & 512 & $10 \times 20$ & $1 \mathrm{k} \times 96$ \\
\hline
\end{tabular}

${ }^{*}{ }^{13} \mathrm{C}$ detection; processed with in-phase anti-phase (IPAP) virtual decoupling.

$\S$ Recorded for some segments to measure ${ }^{1} \mathrm{HN}-{ }^{1} \mathrm{H} \alpha$ coupling constants.

$\uparrow$ Recorded for segments 3, 7 and 8, whose lower sample concentration required more sensitive ${ }^{1} \mathrm{H}$-detected experiments.

T A delay of 10 seconds between pulses was used. Recorded in interleaved mode.

$\$$ Ten spectra with delays of $8,300,36,76,900,100,500,156,200$ and 16 ms were recorded. 


\section{Sup. Fig. 1}

Biophysical Characterization of the Complete hCPEB3 IDR
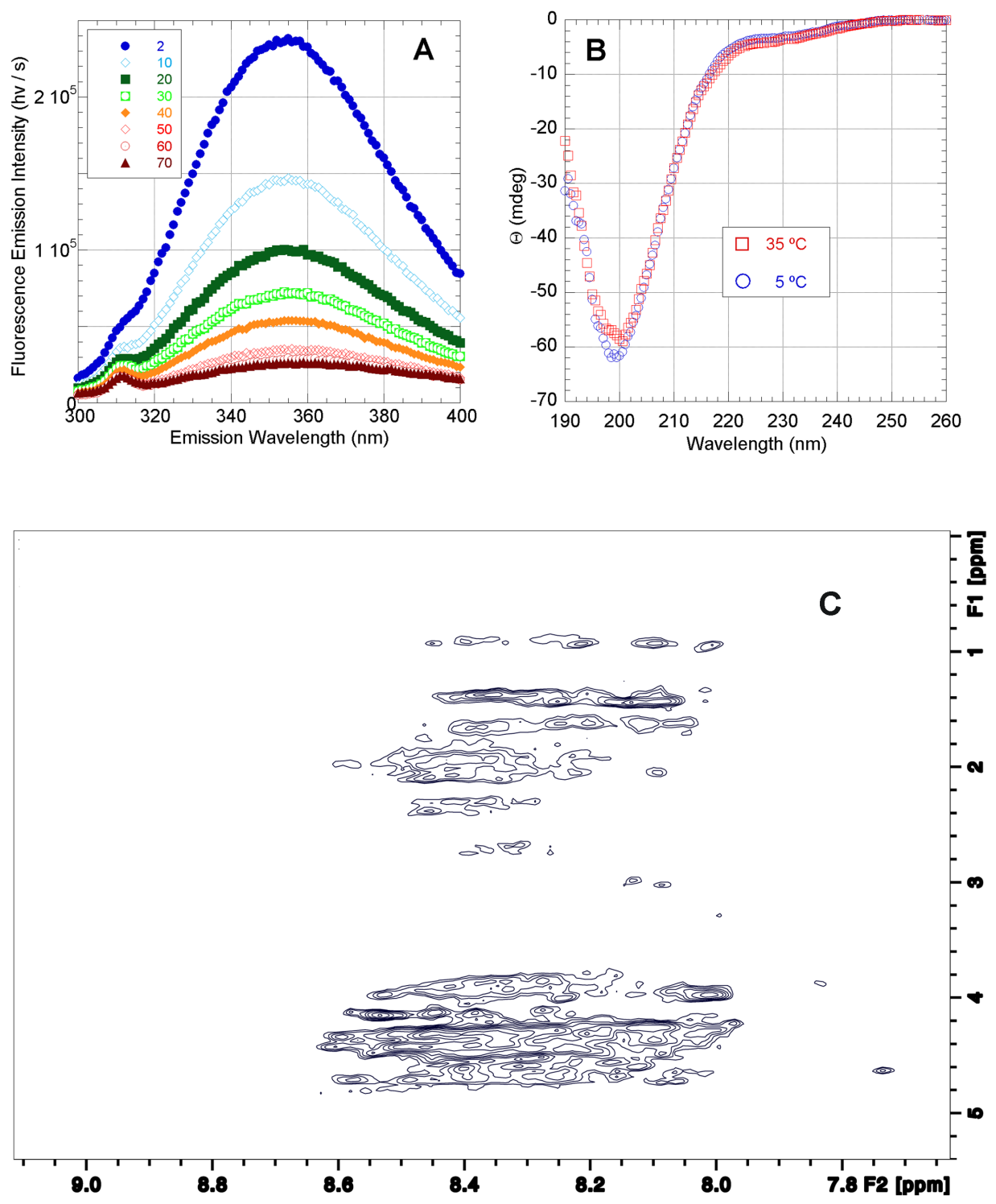

A. Fluorescence emission spectra of the complete IDR of hCPEB3 at $\mathrm{pH} 4.0$ in $1.0 \mathrm{mM}$ deuterated acetic acid buffer over temperatures ranging from $2{ }^{\circ} \mathrm{C}$ to $70^{\circ} \mathrm{C}$ as indicated. The emission maximum over 350 $\mathrm{nm}$ is indicative of solvent exposed Trp side chains. This is consistent with the lack of a well packed hydrophobic core.

B. Far UV-CD spectra of the IDR of hCPEB3 at $5{ }^{\circ} \mathrm{C}$ (blue open circles) and $35^{\circ} \mathrm{C}$ (red open squares). The observed minimum near $200 \mathrm{~nm}$ and the lack of minima near $208 \mathrm{~nm}, 218 \mathrm{~nm}$ and $222 \mathrm{~nm}$ and the lack of a maximum at $195 \mathrm{~nm}$ are all characteristic spectral features of a statistical coil.

C. $2 \mathrm{D}^{1} \mathrm{H}-{ }^{1} \mathrm{H}$ NOESY spectrum of the hCPEB3 IDR recorded at $25^{\circ} \mathrm{C}$ showing the ${ }^{1} \mathrm{HN}$ crosspeak region. The small chemical shift dispersion in ${ }^{1} \mathrm{HN}(8.6$ to $7.9 \mathrm{ppm})$ is a typical feature of disordered and unfolded proteins (López-Alonso et al., 2010). 
bioRxiv preprint doi: https://doi.org/10.1101/2020.05.12.091587; this version posted May 14, 2020. The copyright holder for this preprint (which was not certified by peer review) is the author/funder, who has granted bioRxiv a license to display the preprint in perpetuity. It is made available under aCC-BY-NC-ND 4.0 International license.

Sup. Fig. 2: Sequence Alignments of CPEB3 from Representative Vertebrates

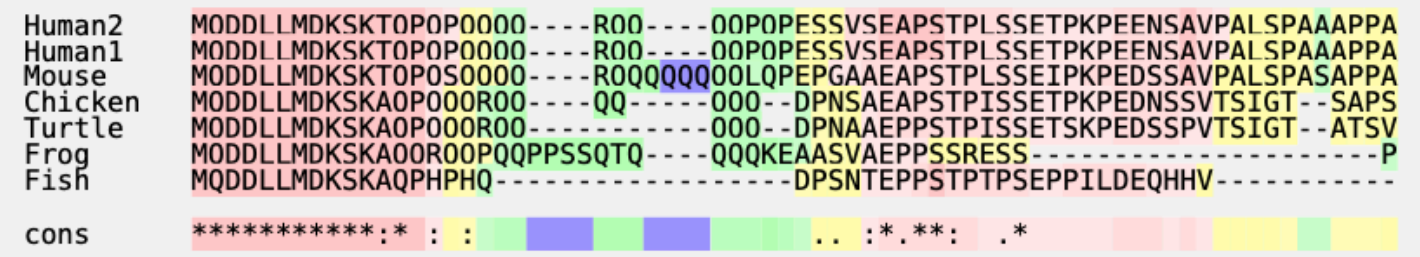

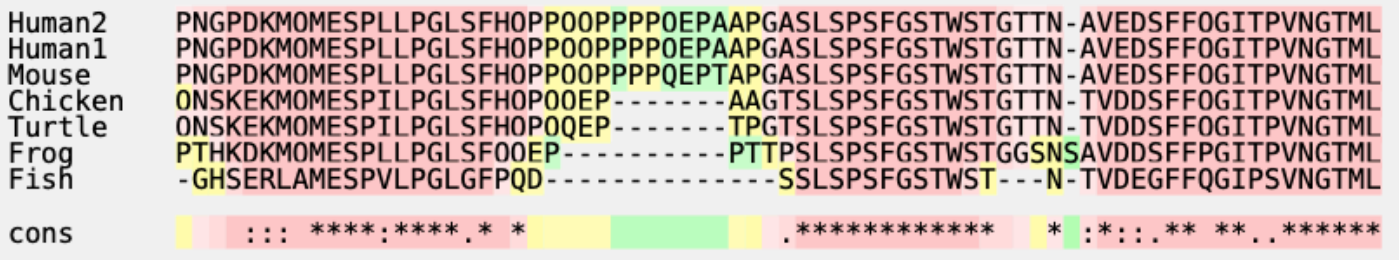

Human2 FONFPH--HVNPVFGGTFSPOIGLAOTOHHOOPPPPAPAPOPAOPAOPPOAOPPOORRSPASPSO-APYAOR FONFPH - - HVNPVFGGTFSPOTGLAOTOHHOOPPPPAPAPOPAOPAOPPOAOPPOORRSPASPSO - APYAOR Mouse FONFPH-- HVNPVFGGTFSPOIGLAOTOHHOOPPPP --APQPPOPAOPPOAOPSOORRSPASPSO-APYAOR Chicken FONFPH--HVNPVFGGTFSPOTGLAOTOHHOH--

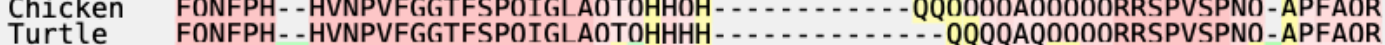
$\begin{array}{ll}\text { Turtle } & \text { FONFPH--HVNPVFGGTFSPOIGLAOTOHHHH } \\ \text { Frog } & \text { FONFPHHHHVNPVFGGTFSPOMGLAHQT-1. }\end{array}$ Fish cons

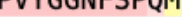

Human2 SAAAAYGHOPIMTSKPSSSSAVAAAAAAAAASSASSSWNTHOSVNAAWSAPSNPWGGLOAGRDPRRAVGVGV Human1 SAAAAYGHOPIMTSKPSSSSAVAAAAAAAAASSASSSWNTHOSVNAAWSAPSNPWGGLOAGRDPRRAVGVGV Mouse SA-AAYGHOPIMTSKPSSSSAVAAAAAAAAASSASSSWNTHOSVNAAWSAPSNPWGGLOAGRDPRRAVGVGV Chicken NA--AYSHOPIMTSKPSSSS-.....-ASSSSSSSWNNHO--NAAWSTPSNPWGGLOAGRDPRRAVGVGV Turtle NA--AYSHOPIMTSKPSSSS - .......-ASSSSSSSWNNHO - NAAWSTPSNPWGGLOAGRDPRRAVGVGV

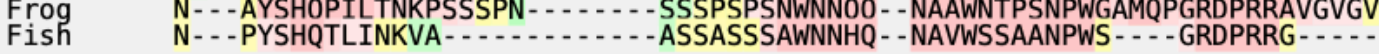

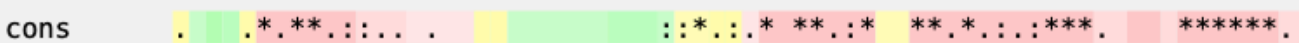

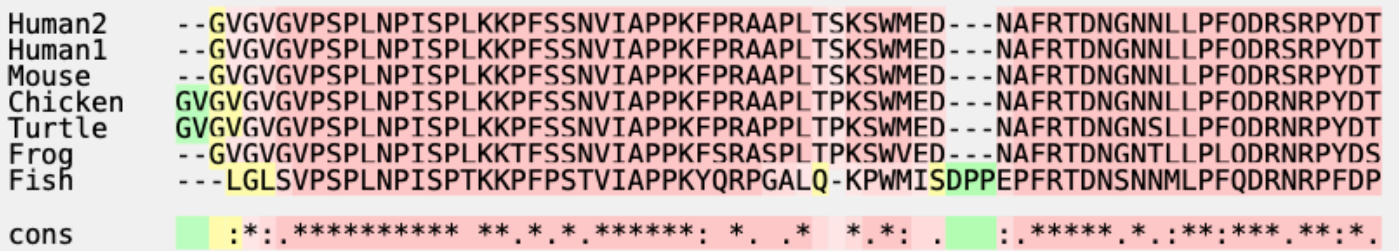

cons

\begin{tabular}{|c|c|}
\hline $\begin{array}{l}\text { Human2 } \\
\text { Human1 } \\
\text { Mouse }\end{array}$ & $\begin{array}{l}\text { FNLHSLENSLMDMIRTDHEPLK } \\
\text { FNLHSLENSLMDMIRTDHEPLKGKHYPSGPPMSFADIMWRNH } \\
\text { FNLHSLENSLMDMIRTDHEPLKGKHYPPSGPPMSFADIMWRNH }\end{array}$ \\
\hline $\begin{array}{l}\text { Chicken } \\
\text { Turtle } \\
\text { Frog } \\
\text { Fish }\end{array}$ & $\begin{array}{l}\text { FNLHSLENSLMDMIRTDHEPLKGKHYPPSGPPMSFADIMWRNH } \\
\text { FNLHSLENSLMDMIRTDHEPLKGKHYPPSGPPMSFADIMWRNH } \\
\text { FNLHTLENSLMDMIRTDHEPLK } \\
\text { FNLQTLENSLMDMIKNDHD--KGKHHPAAGPPMTIADILWRNH }\end{array}$ \\
\hline cons & $* * *:: * * * * * * * * *: . * *: \quad *$ \\
\hline $\begin{array}{l}\text { Human2 } \\
\text { Human1 } \\
\text { Mouse } \\
\text { Chicken } \\
\text { Turtle } \\
\text { Frog } \\
\text { Fish }\end{array}$ & 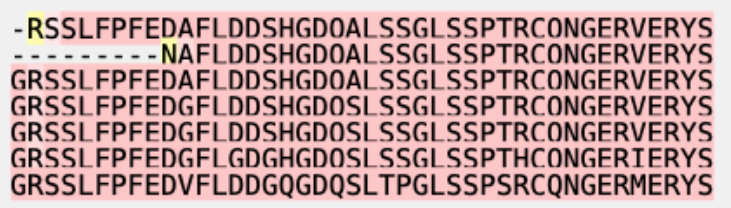 \\
\hline cons & : **.*.: :***:*:. $* * * * *:: * * * * * *: * * * *$ \\
\hline
\end{tabular}

Results obtained using T-coffee, version 11 (Di Tommaso et al., 2011) using default settings. Sequence is highlighted using a red to blue color scale for highly to poorly conserved residues, respectively. Note that because of the small space between lines, some "Q"s appear as "O"s. "Cons" indicates the level of sequence conservation: "“*” = strictly conserved, ":" = well conserved, "." moderately conserved. 
Sup. Fig. $32 \mathrm{D}{ }^{1} \mathrm{H}-{ }^{15} \mathrm{~N}$ HSQC NMR Spectrum of hCPEB3, Segment 4

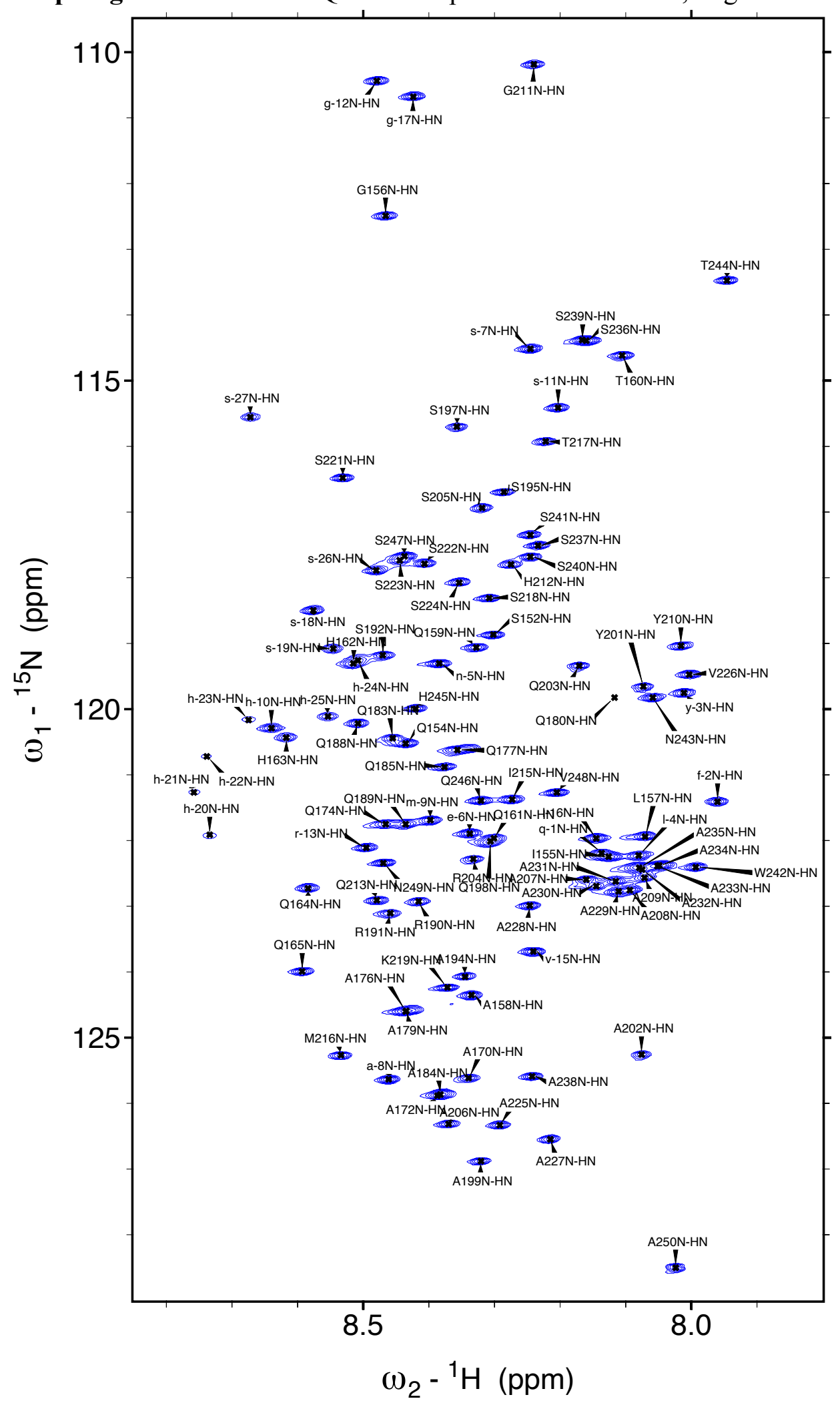

${ }^{1} \mathrm{H}-{ }^{15} \mathrm{~N}$ correlations were recorded at $25^{\circ} \mathrm{C}$ in $1 \mathrm{mM}$ acetic acid, $\mathrm{pH}$. Note the cluster of Ala signals in belonging to the polyA stretches near $8.05 \mathrm{ppm}{ }^{1} \mathrm{H}$ and $122.5 \mathrm{ppm}{ }^{15} \mathrm{~N}$. Their position contrasts with those of the isolated Ala residues, whose $\delta{ }^{15} \mathrm{~N}>125 \mathrm{ppm}$. Signals labeled in lower case with

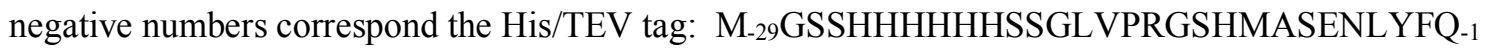


Sup. Fig. $42 \mathrm{D}{ }^{13} \mathrm{CO}-{ }^{15} \mathrm{~N}$ NMR Spectrum of hCPEB3

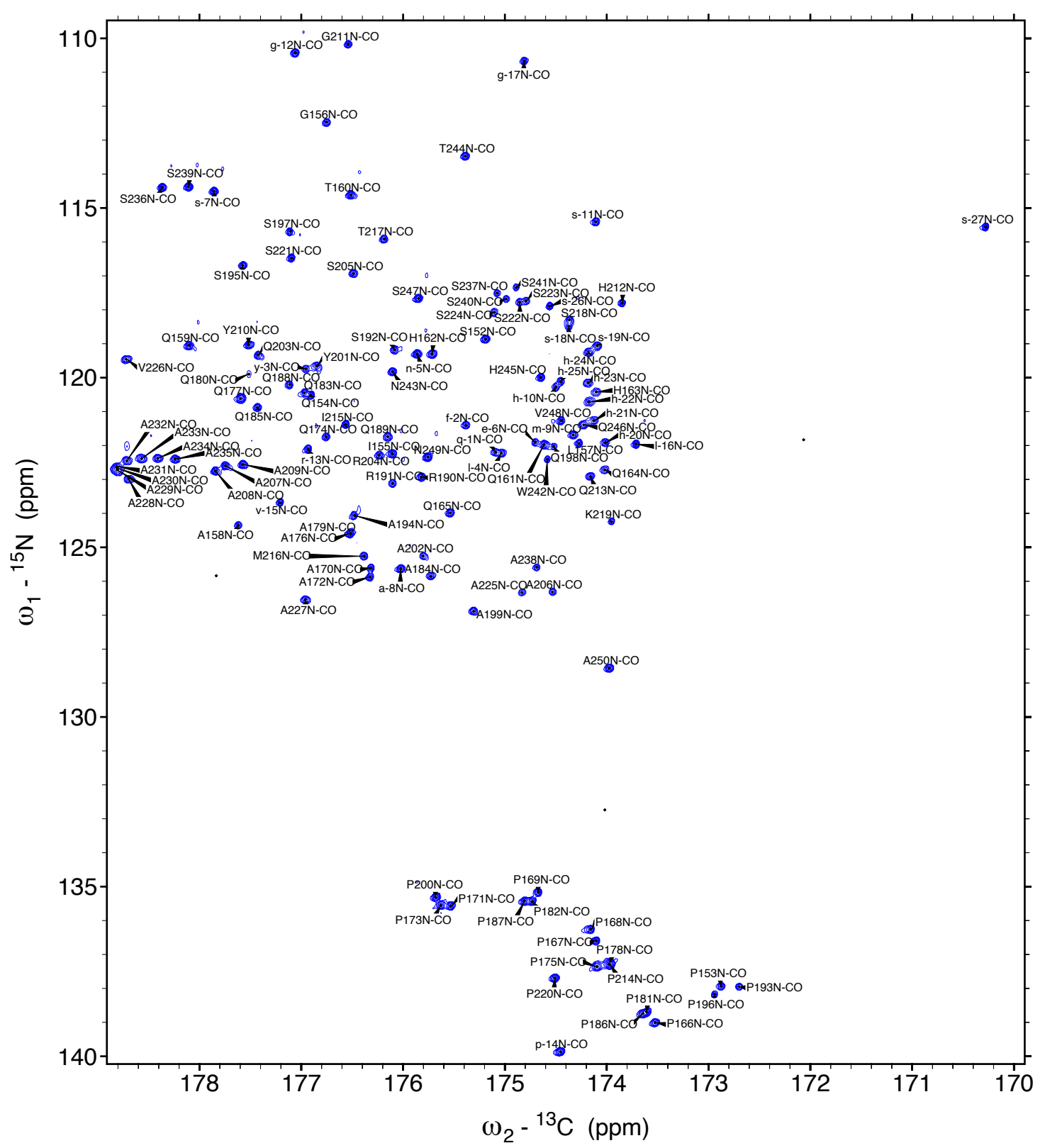

${ }^{13} \mathrm{CO}-{ }^{15} \mathrm{~N}$ correlations were recorded at $25^{\circ} \mathrm{C}$ in $1 \mathrm{mM}$ acetic acid, $\mathrm{pH} 4$. Here, the signals of the long polyAla stretch, which appears around $122.5 \mathrm{ppm}$ for ${ }^{15} \mathrm{~N}$ x $178.5 \mathrm{ppm}$ for ${ }^{13} \mathrm{CO}$ shows superior resolution relative to the ${ }^{1} \mathrm{H}^{15} \mathrm{~N}$ HSQC spectrum. Their position at higher ${ }^{13} \mathrm{CO}$ and lower ${ }^{15} \mathrm{~N}$ chemical shift values relative to isolated Ala and to coil values indicates an alpha helical conformation. For simplicity, the label refers to the ${ }^{13} \mathrm{CO}$ of the $i-1$ residue. Signals labeled in lower case with negative numbers correspond the His/TEV tag: $\mathrm{M}_{-29}$ GSSHHHHHHSSGLVPRGSHMASENLYFQ-1 
Sup. Fig. 5. Corroboration of small to negligible populations of $\alpha$-helix or $\beta$-strand conformations in residues $91-110$ of hCPEB3.
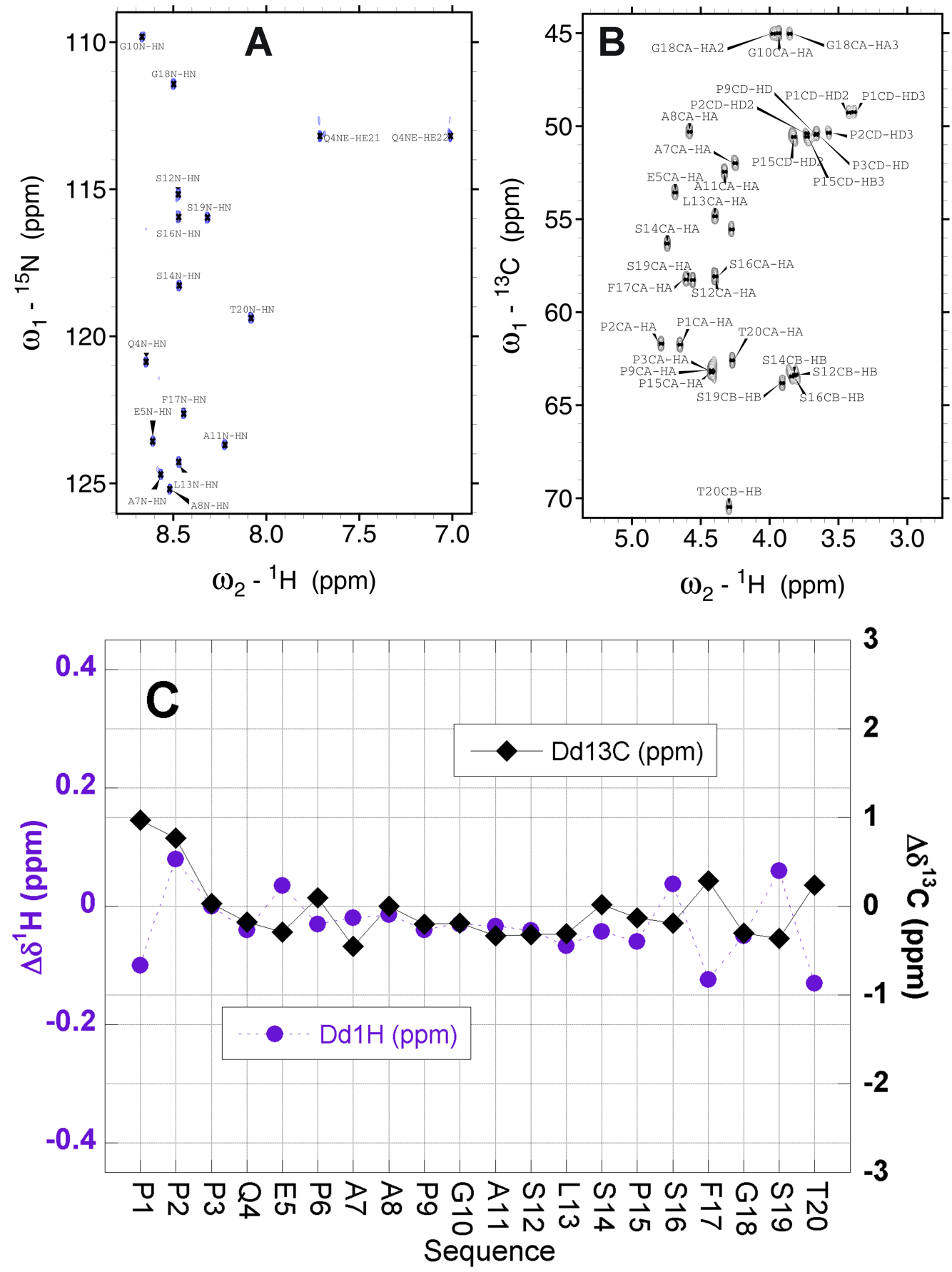

A. The assigned ${ }^{1} \mathrm{H}^{-15} \mathrm{~N}$ HSQC spectrum of a peptide corresponding to residues $91-110$ of hCPEB3. The low chemical shift dispersion in the ${ }^{1} \mathrm{HN}$ dimension is a hallmark of a statistical coil. The residue number labels correspond to this peptide, to calculate the residue number in the full length protein, add 90.

B. The ${ }^{1} \mathrm{H}-{ }^{13} \mathrm{C}$ HSQC spectrum of the same peptide, showing the assigned ${ }^{1} \mathrm{H} \alpha-{ }^{13} \mathrm{C} \alpha,{ }^{1} \mathrm{H} \delta-{ }^{13} \mathrm{C} \delta$ Pro and ${ }^{1} \mathrm{H} \beta-{ }^{13} \mathrm{C} \beta$ Ser \& Thr correlations.

C. Conformational chemical shifts of ${ }^{1} \mathrm{H} \alpha$ (left y-axis, purple circles) and ${ }^{13} \mathrm{C} \alpha$ (right y-axis, black diamonds). Values of $-0.41 \mathrm{ppm}\left({ }^{1} \mathrm{H}\right)$ and $+3.1 \mathrm{ppm}\left({ }^{13} \mathrm{C}\right)$ correspond to $100 \% \alpha$-helix and values of +0.41 $\left({ }^{1} \mathrm{H}\right)$ and $-3.1 \mathrm{ppm}\left({ }^{13} \mathrm{C}\right)$ correspond to $100 \% \beta$-strand. Here residues show small conformation chemical shifts except for $\mathrm{N}$ - and $\mathrm{C}$-termini, whose values are perturbed by end effects, and residues near Phe 17 (Phe 107 in the full length protein) whose values are altered by ring current effects. 
Sup. Fig. 6 Partial Formation of an $\alpha$-Helix in the N-terminal Residues of hCPEB3
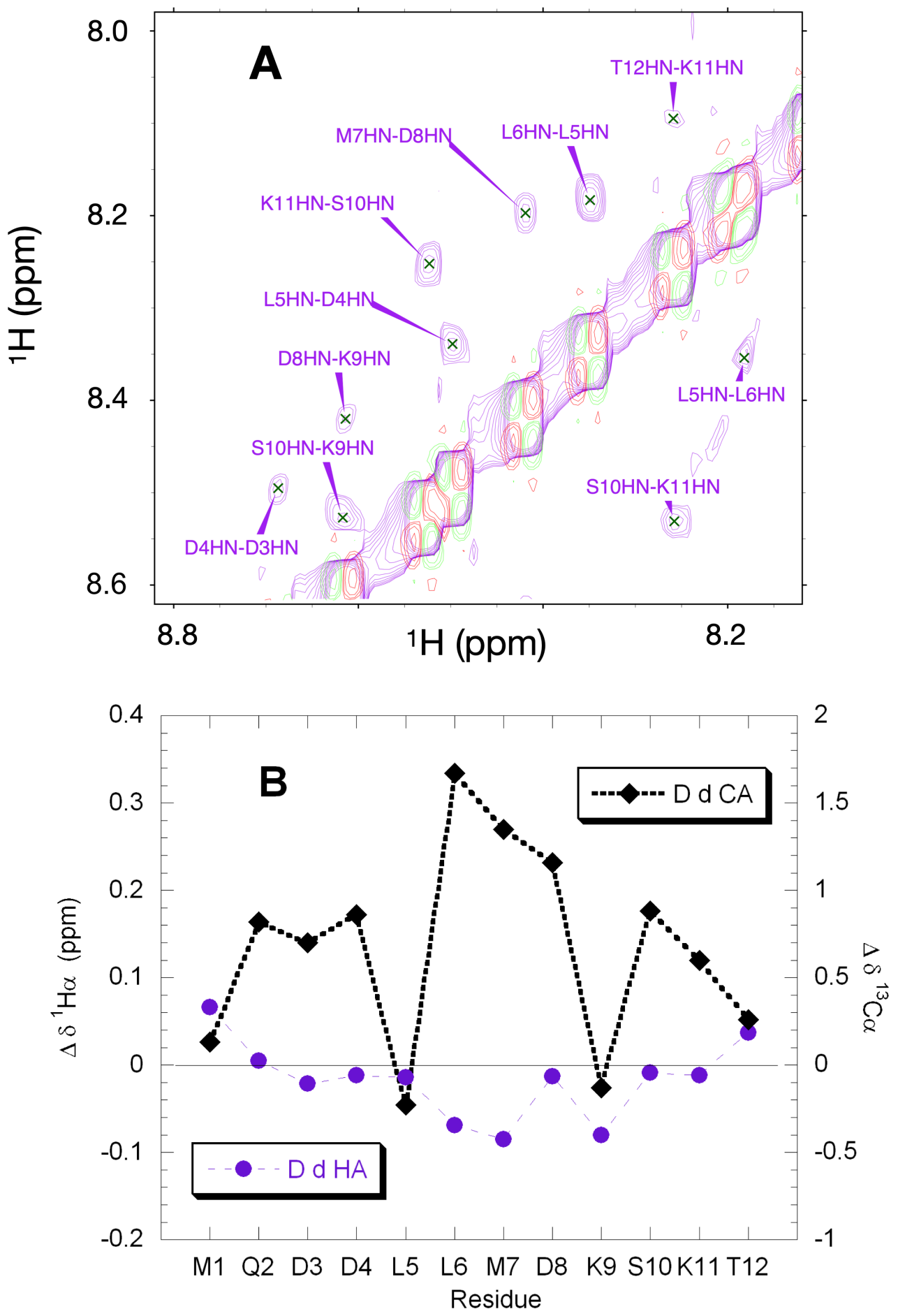

A. $2 \mathrm{D}{ }^{1} \mathrm{H}-{ }^{1} \mathrm{H}$ NOESY ( $80 \mathrm{~ms}$ mixing time, purple) of a peptide corresponding to the initial residues of hCPEB3. Sequential NOE correlations, which are consistent with $\alpha$-helical structure, are labeled. Red and green peaks along the diagonal are from the $2 \mathrm{D}^{1} \mathrm{H}-{ }^{1} \mathrm{H}$ COSY spectrum.

B. Conformational ${ }^{1} \mathrm{H}$ (purple) and ${ }^{13} \mathrm{C}$ (black) chemical shifts at $5{ }^{\circ} \mathrm{C}$ for a peptide corresponding to the initial residues of hCPEB3 $20 \%$ hexafluoroisopropanol $\left(\mathrm{CF}_{3}-\mathrm{CHOH}-\mathrm{CF}_{3}\right)$ The positive $\Delta \delta^{13} \mathrm{C}$ and negative $\Delta \delta{ }^{1} \mathrm{H}$ values are indicative of the formation of significant $\alpha$-helix formation. 
Sup. Fig. 7 The Consecutive Proline Residues of hCPEB3 show a Characteristic Pattern of Conformational Chemical Shifts.

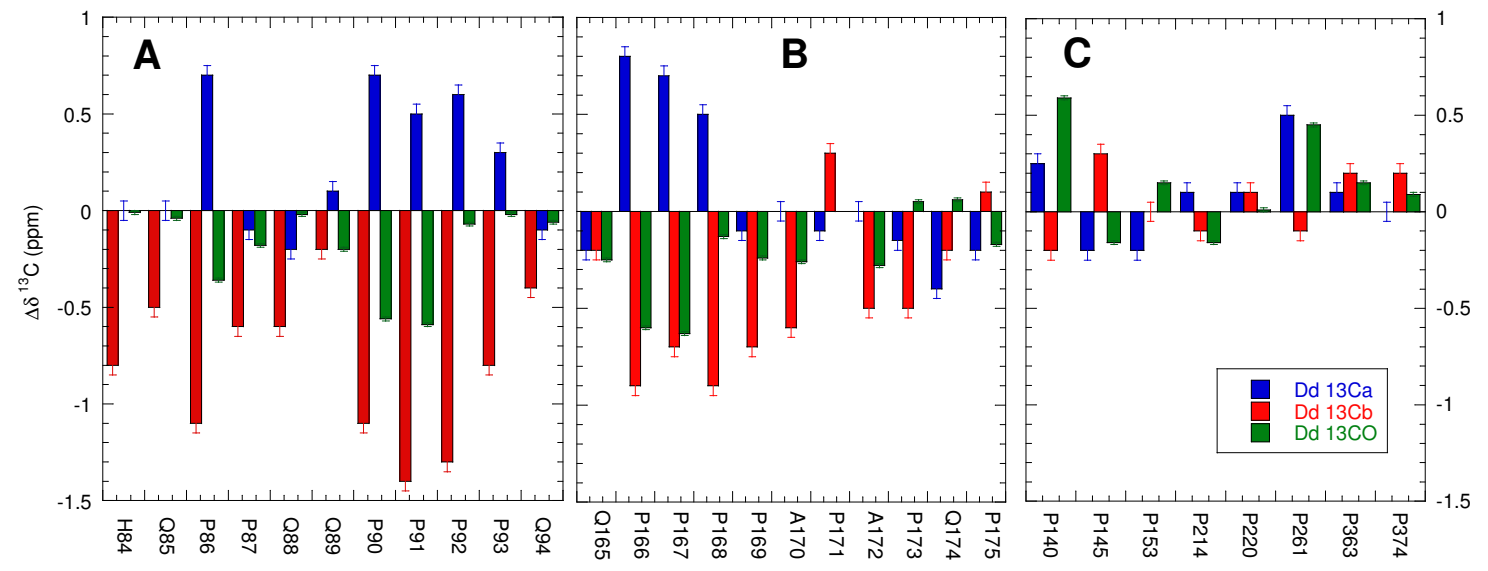

A. and B. Conformational chemical shifts $\left(\Delta \delta\right.$ ) for ${ }^{13} \mathrm{C} \alpha$ (blue bars), ${ }^{13} \mathrm{C} \beta$ (red) and ${ }^{13} \mathrm{CO}$ (green) nuclei for residues in two Pro-rich stretches, H84-Q94 and Q165-175, each of which contains four consecutitive Proline residues which will be locked in the polyproline II helical conformation. The $\Delta \delta$ values of residues $\mathrm{P} 90, \mathrm{P} 91, \mathrm{P} 92, \mathrm{P} 168, \mathrm{P} 167$ and $\mathrm{P} 168$ were averaged to obtain the values given in Table 3 on the main text.

C. Isolated proline residues, i.e. those which do not have another proline residue within two anterior or posterior positions along the sequence, do not show a pattern of significant $\Delta \delta$ deviations. 
Sup. Fig. 8. Residue Level Dynamics of hCPEB3’s Instrinsically Disordered Region
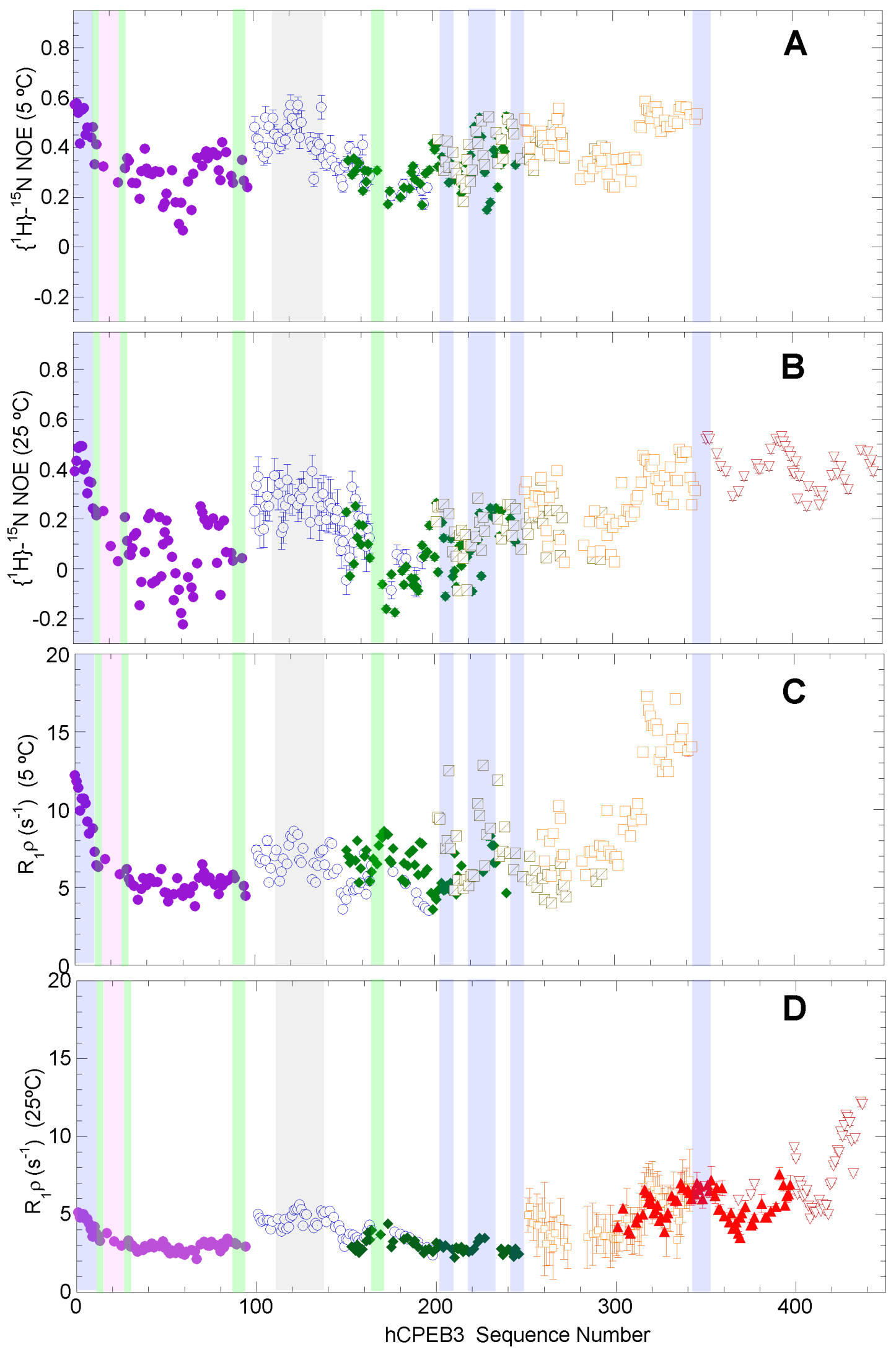

Residue-level dynamics on ns/ps time scales at $5^{\circ} \mathrm{C}(\mathbf{A})$ and $25^{\circ} \mathrm{C}(\mathbf{B})$ and on $\mu \mathrm{s} / \mathrm{ms}$ at $5^{\circ} \mathrm{C}(\mathbf{C})$ and $25^{\circ} \mathbf{C}(\mathbf{D})$. In panels $\mathbf{A}$ and $\mathbf{B}$, a value of 0.86 is expected for completely rigid $\mathrm{H}-\mathrm{N}$ groups; negative values are characteristic of a high flexibility. In panels $\mathbf{C}$ and $\mathbf{D}$, while values less than $4 \mathrm{~s}^{-1}$ are hallmarks of 
bioRxiv preprint doi: https://doi.org/10.1101/2020.05.12.091587; this version posted May 14, 2020. The copyright holder for this preprint (which was not certified by peer review) is the author/funder, who has granted bioRxiv a license to display the preprint in perpetuity. It is made available under aCC-BY-NC-ND 4.0 International license.

flexibility, higher values mean decreased mobility. Data from individual segments are colored differently: segment 1 = purple filled circles, segment $3=$ blue open circles, segment $4=$ green diamonds, segment $5=$ brown barred open squares, segment $6=$ orange open squares, segment $7=$ filled red triangles, segment $8=$ open inverted maroon triangles. No data are represented for segments 7 and 8 at $5^{\circ} \mathrm{C}$, segment 5 in panel $\mathbf{D}$, and segment 7 in panel $\mathbf{B}$ as the spectra obtained were of insufficient quality. The lack of other values is due to ${ }^{1} \mathrm{H}^{15} \mathrm{~N}$ signal overlap or proline residues whose nitrogen lacks a hydrogen. Error bars represent uncertainties as estimated from peak intensity signal/noise for panels $\mathbf{A}$ and $\mathbf{B}$ and as obtained from the fit of a signal exponential decay function to the peak intensity versus delay time data for panels $\mathbf{C}$ and $\mathbf{D}$. The error bar is frequently smaller than the data symbol.

Elements of partial structure/interest are shaded blue for $\alpha$-helices and gray for hydrophobic segments; these elements generally show decreased mobility. By contrast, the polyQ tract (shaded magenta) is more flexible. Whereas the dynamics of the PPII tracts (green) can now be assessed directly as these imine residues lack ${ }^{1} \mathrm{HN}$, nearby residues do show relatively high mobility. 
Sup. Fig. 9. ${ }^{1} \mathrm{HN}-{ }^{1} \mathrm{H} \alpha$ Coupling Constants for Segment 5

Confirm the Presence of $\alpha$-Helices.

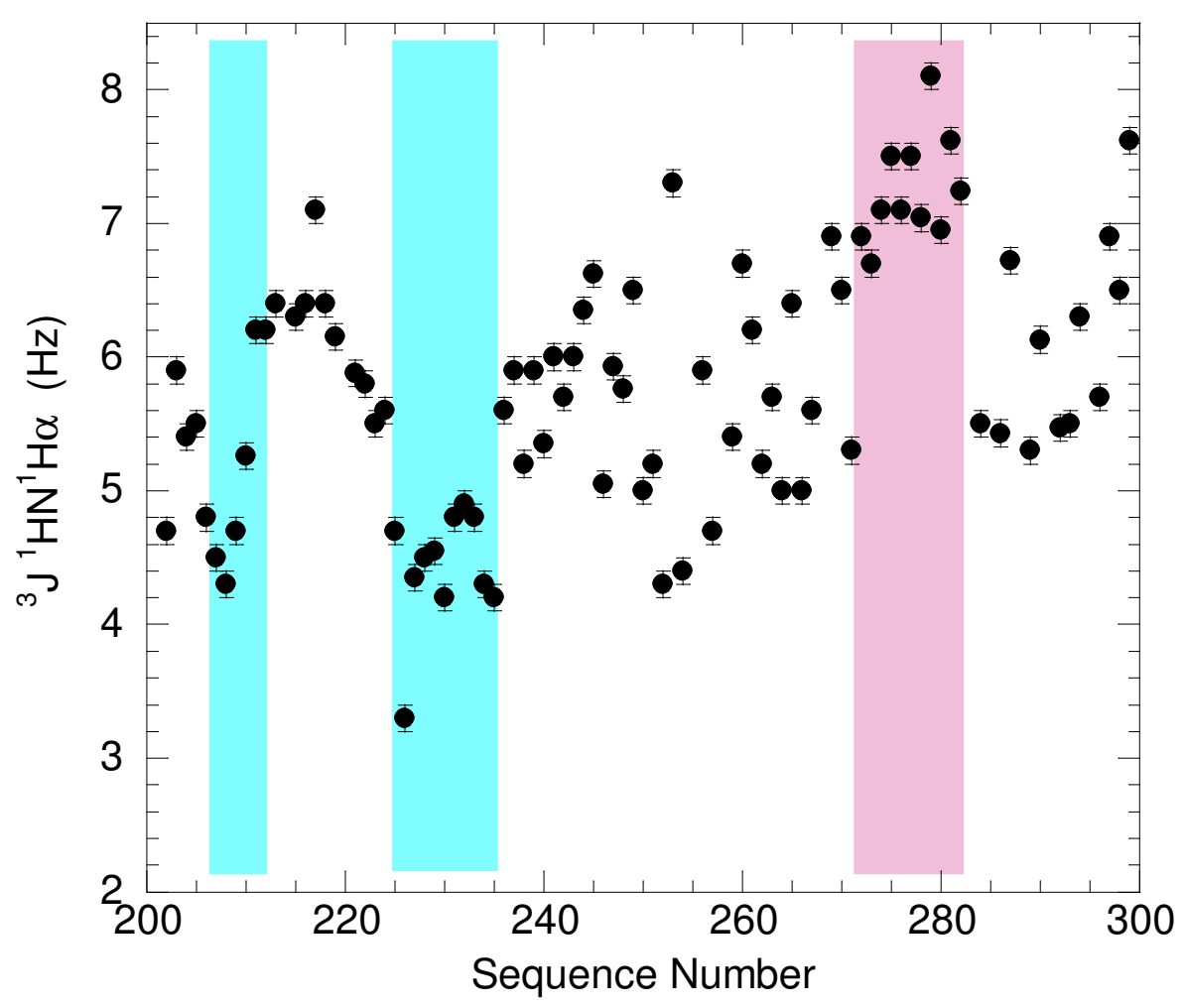

Intraresidual three bond ${ }^{1} \mathrm{HN}-{ }^{1} \mathrm{H} \alpha$ coupling constants $\left({ }^{3} \mathrm{~J}_{1 \mathrm{HN} 1 \mathrm{H} \alpha}\right)$ for segment 5 of hCPEB3. Regions with ${ }^{3} \mathrm{~J}_{1 \mathrm{HN} 1 \mathrm{H} \alpha}<5$ (shaded cyan) correspond to two $\alpha$-helices, in line with the results based on chemical shift deviations (see Fig. 3 in the Main Text). A zone with ${ }^{3} \mathrm{~J}_{1 \mathrm{HN} 1 \mathrm{H \alpha}}>7 \mathrm{~Hz}$ (shaded rose) indicates extended conformations. This zone spans the $(\mathrm{VG})_{5}$ motif. 
Sup. Fig. 10. Helices from Pathological and Functional Amyloids Are Stabilized by Distinct Interactions.
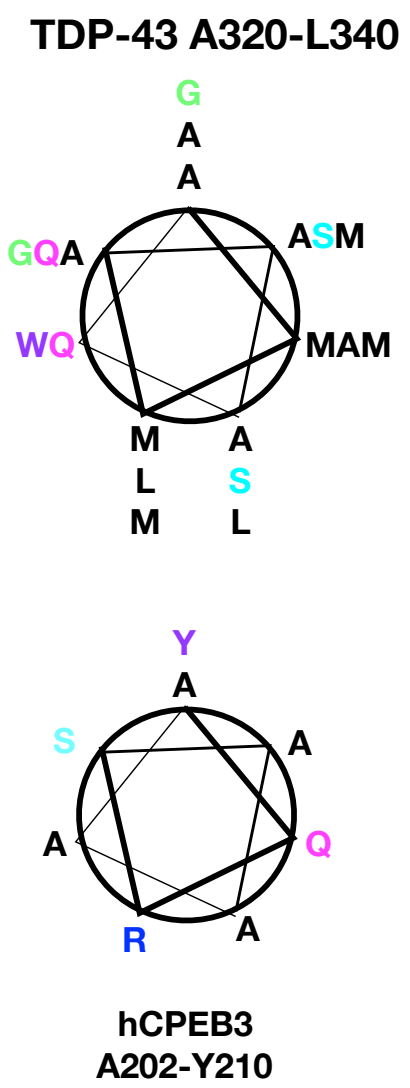

\section{ApCPEB}

I36-V49

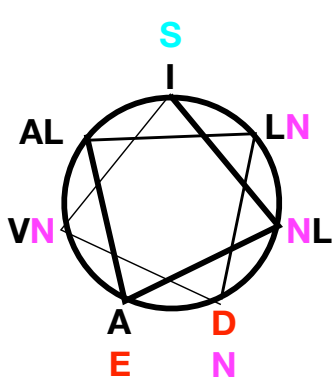

A

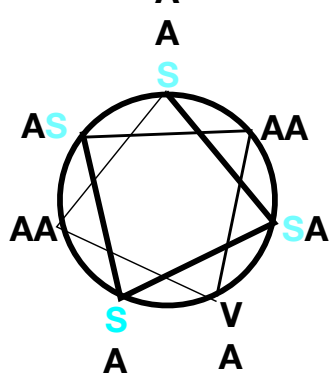

hCPEB3

A221-A235
Orb2A

M1-C12

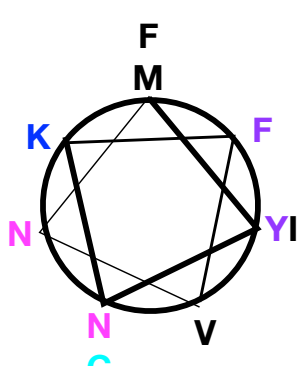

C

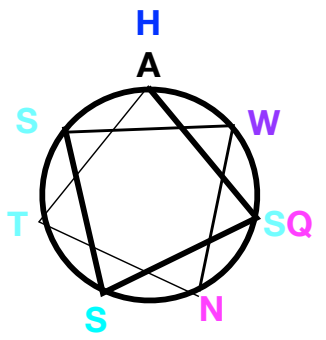

hCPEB3

A238-Q246
hCPEB3

M1-T12
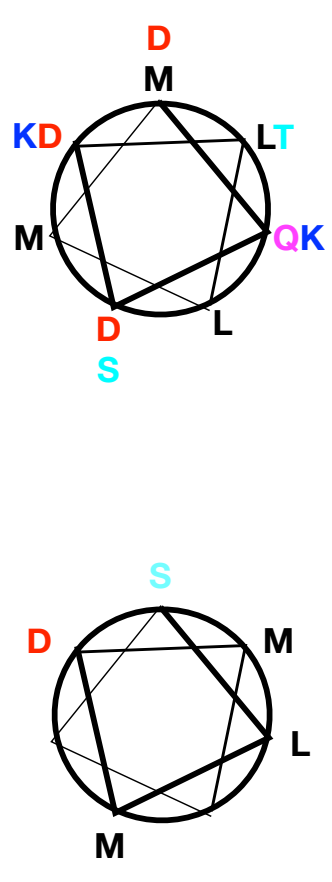

hCPEB3

S352-M356

Helical wheel diagrams of TDP-43, ApCPEB, Orb2A and hCPEB3, nonpolar residues are colored black, aromatics=purple, $\mathrm{Q} / \mathrm{N}=$ magenta, $\mathrm{E} / \mathrm{D}=$ red, $\mathrm{H} / \mathrm{K} / \mathrm{R}=$ blue, $\mathrm{G}=$ green, $\mathrm{C}, \mathrm{S}, \mathrm{T}=$ cyan. The five hCPEB3 helices were identified here by NMR data. The TDP-43 helix was identified by NMR by Lim et al., 2016. The ApCPEB and Orb2A helices are putative as they have not yet been confirmed experimentally.

Lim, L., Wei, Y., Lu, Y., \& Song, J. (2016). ALS-Causing Mutations Significantly Perturb the SelfAssembly and Interaction with Nucleic Acid of the Intrinsically Disordered Prion-Like Domain of TDP43. PLoS biology, 14(1), e1002338. https://doi.org/10.1371/journal.pbio.1002338 